\title{
IDŐJÁRÁS
}

Quarterly Journal of the Hungarian Meteorological Service

Vol. 125, No. 4, October-December, 2021, pp. 521-553

\section{Recent developments in the data assimilation of AROME/HU numerical weather prediction model}

\author{
Helga Tóth ${ }^{1, *}$, Viktória Homonnai ${ }^{1}$, Máté Mile ${ }^{2}$, Anikó Várkonyi ${ }^{1}$, \\ Zsófia Kocsis ${ }^{1}$, Kristóf Szanyi ${ }^{1}$, Gabriella Tóth ${ }^{1}$, Balázs Szintai ${ }^{1}$, \\ and Gabriella Szépszó ${ }^{1}$
}

${ }^{1}$ Hungarian Meteorological Service

P.O. Box 38, H-1525 Budapest, Hungary

${ }^{2}$ Norwegian Meteorological Institute

P.O. Box 43, Blindern, N-0313 Oslo, Norway

*Corresponding authors E-mail: toth.h@met.hu

(Manuscript received in final form August 12, 2021)

\begin{abstract}
A local three-dimensional variational data assimilation (DA) system was implemented operationally in AROME/HU (Application of Research to Operations at Mesoscale) non-hydrostatic mesoscale model at the Hungarian Meteorological Service (OMSZ) in 2013. In the first version, rapid update cycling (RUC) approach was employed with 3-hour frequency in local upper-air DA using conventional observations only. Optimal interpolation method was adopted for the surface data assimilation later in 2016. This paper describes the current developments showing the impact of more conventional and remotesensing observations assimilated in this system, which reveals the benefit of additional local high-resolution observations. Furthermore, it is shown that an hourly assimilationforecast cycle outperforms the 3-hourly updated system in our DA. Besides the upper-air assimilation developments, a simplified extended Kalman filter (SEKF) was also tested for surface data assimilation, showing promising performance on both the analyses and the forecasts of AROME/HU system.
\end{abstract}

Key-words: data assimilation, simplified extended Kalman filter, rapid update cycle, aircraft observations, atmospheric motion vectors 


\section{Introduction}

Accurate estimation of the atmospheric initial state is an essential prerequisite for high-quality weather forecasts. Global numerical weather prediction (NWP) models use all information available about the Earth system to determine the initial condition: different kinds of observations, previous weather forecasts (called as background or first guess), and a priori physical information. They are combined in a statistically optimal way based on their reliability using data assimilation (DA) techniques. In the recent operational practice, three algorithms are widely applied in global models: the optimal interpolation (OI) minimizes the quadratic difference between the analysis and the truth; the variational method is based on minimization of a cost function measuring the analysis departures from the observations and the first guess; the Kalman filter method takes into account the flow-dependency of background errors. Variational methods are mostly utilized for upper-air data assimilation (Fischer et al., 2005; Courtier et al., 1994): in the 3-dimensional and 4-dimensional (3DVar and 4D-Var) versions, the procedure looks for the best fit to background and observations at the analysis time and along a trajectory, respectively. OI is employed in surface data assimilation (Mahfouf et al., 2000), as it is the simplified extended version of the Kalman filter (SEKF) (de Rosnay et al., 2013; Mahfouf, 2009) which allows involving also satellite measurements in exchange for its higher computational cost.

For limited area models (LAMs), dynamical adaptation is a plausible way to prepare initial conditions without complex and computationally expensive methods. In this simple technique, the coarser-resolution driving model fields are interpolated onto the higher resolution target grid in the initial time step. The first limited area model of the ALADIN (Aire Limitée Adaptation dynamique Développement InterNational) consortium was originally developed without data assimilation, and in its earliest version at the Hungarian Meteorological Service (OMSZ) the initial conditions were created by dynamical adaptation (Horányi et al., 1996), i.e., interpolating the fields of the global NWP model of Météo-France, ARPEGE (Action de Recherche Petite Echelle Grande Echelle) to the ALADIN grid. Nevertheless, only local and dense observations ensure to have access to those small-scale atmospheric features which are crucial for high-resolution mesoscale weather forecasts. The incremental 3D-Var algorithm was implemented to ALADIN, which looks for the minimum of departure between the analysis and the background field assuming that the background is a good estimation of the analysis and the linearized version of the observation operator can be used during the computation of the minimization. This is the standard or regularized linear least squares problem (Fischer, 2007). The method was introduced into the operational ALADIN version of OMSZ in 2005 (referred as ALADIN/HU; Bölöni, 2006). In the beginning, it assimilated only conventional observations (SYNOP, TEMP, temperature, and horizontal wind components 
measured by aircrafts) 4 times a day at $0,6,12$, and 18 UTC, and it was gradually extended with a variety of satellite data and wind profiler measurements (Randriamampianina, 2006).

The AROME (Application of Research to Operations at Mesoscale) model consists of the non-hydrostatic dynamical core of ALADIN, the atmospheric physical parameterization of the Meso-NH research model, and the SURFEX surface model (Seity et al., 2011). It has been running operationally at OMSZ over a domain covering the Carpathian Basin with $2.5 \mathrm{~km}$ horizontal resolution and 60 vertical levels since 2010 (Szintai et al., 2015). The initial and lateral boundary conditions (LBCs) were first taken from ALADIN/HU, benefiting from the already existing coarser resolution LAM analyses. However, it was proven later that the interpolated analysis does not contain reliable physical information on the smallest scales resolved by AROME/HU and in addition, more observations can be used at higher resolution. Therefore, the implementation of the local AROME DA system was started and the upper-air 3D-Var system became operational in 2013, assimilating conventional data (Mile et al., 2015).

The 3D-Var approach assumes that all observations inside the assimilation window are measured exactly at the analysis time generating increased representation error in time. In order to be able to use more observations with reduced temporal representation error, experiments have been started with hourly analysis updates (i.e., rapid update cycle, RUC) in 2018 (Jávorné Radnóczi et al., 2020).

The raw analysis often exhibits some imbalances which primarily originate from inconsistencies between the observed mass and wind fields inducing highfrequency oscillations in the first hours of the forecasts. In ALADIN/HU, a digital filter initialization (Lynch et al., 1997) is applied to the analysis, which removes the high-frequency waves from the initial condition during a forward and backward model integration. This filtering technique is assumed to be detrimental for the mesoscale spectrum of AROME model, thus not employed in AROME/HU. Instead, a space consistent coupling is used, i.e., the LBC at the initial time is provided by the AROME/HU analysis, which efficiently exempts from high amplitude oscillating noises (Mile et al., 2015).

Representation of background error statistics has key importance in variational methods, as the background error covariance matrix (the so-called B matrix) controls the propagation of the information coming from observations to the model grid and variables (Berre, 2000). The B matrix in ALADIN/HU was originally estimated with the NMC method (NMC stands for National Meteorological Center) that samples the forecast errors from a set of differences between two forecasts valid at the same time, but at different ranges (Parish and Derber, 1992). Later the ensemble technique was introduced, where the background errors are approximated by subtracting the members of an ensemble forecast generated with a set of data assimilation cycles (EDA) using perturbed observations that induce a spread also among the first guess fields through the 
cycling (Bölöni et al., 2014). The ensemble was first created by downscaling an ensemble of ARPEGE lateral boundary conditions using ALADIN (Bölöni, 2006), but later it was originating from the ALADIN ensemble prediction system (EPS) of OMSZ (Hágel, 2009). EDA method was applied to compute the background errors also in the case of AROME/HU: initially with downscaling the ensemble of ALADIN LBCs and recently with a 5-member ensemble provided by the convection-permitting AROME-EPS system (Jávorné Radnóczi et al., 2020).

The initial conditions for the soil scheme in the early version of ALADIN/HU were interpolated from the ARPEGE analysis fields. In 2008, the CANARI optimal interpolation (Taillefer, 2002; Tóth, 2004) was implemented, in which the soil temperature and moisture analyses are calculated based on the relationship between soil and near-surface variables. In AROME/HU, the surface analysis of ALADIN/HU was interpolated to the $2.5 \mathrm{~km}$ resolution grid initially, while an improved version of the optimal interpolation was adopted in 2016. At the same time, experiments were started with simplified extended Kalman filter to exploit the advantage of the new observation techniques (like remote sensing data).

An obvious way to develop a data assimilation system is to involve new observations. Hourly analysis update requires to supply the assimilation with frequently and reliably available data. The DFS (degrees of freedom for signal) diagnostic tool (Cardinali et al., 2004) indicates the relative contribution of given observations to the analysis. In a previous study (Mile et al., 2015), DFS scores showed the large contribution of wind measurements and suggested the importance of humidity-related observations. In the last few years, sensitivity studies have been started in ALADIN/HU and more intensively in AROME/HU to estimate the impact of atmospheric motion vectors derived from satellite images, radial wind measured by meteorological radars, temperature, and wind information registered by the radars of air traffic controllers (i.e., Mode-S observations); radar reflectivity, zenith total delay (ZTD) observations of GNSS (global navigation satellite systems), and humidity observed by aircrafts (Mile et al., 2015, 2019; Fischer et al., 2017, 2018).

This paper aims to provide a comprehensive overview of current DA developments. In Section 2, the operational DA system is described. In Section 3, the local, experimental DA studies are represented applying conventional and non-conventional observations, as additional Mode-S MRAR (Meteorological Routine Air Report) data and satellite atmospheric motion vectors. Besides this, the surface data assimilation and RUC related developments are also presented in this Section. Finally, a summary of the recent results and further potential research are provided. 


\section{The operational data assimilation system of AROME/HU model}

The data assimilation system of the operational AROME/HU model consists of an incremental 3D-Var and an OI technique for the upper-air and surface analysis, respectively. Furthermore, this system composes a three-hourly updated forward intermittent cycle called RUC (Benjamin et al., 2004; Mile et al., 2015, Szintai et $a l ., 2015)$. The LBCs are provided by the ECMWF/IFS (European Centre for Medium-Range Weather Forecasts / Integrated Forecasting System) model at hourly time intervals. The current operational AROME/HU version has been based on the cy43t 2 model cycle since March 2021, and it has run at $2.5 \mathrm{~km}$ horizontal resolution, with 60 hybrid pressure terrain-following vertical levels. Most of the developments (except for SEKF) shown in this paper were carried out with the previous operational model version, cy40t1 (the 'cy' refers to the model 'cycle'; cycle number 40 is derived from the corresponding IFS cycle, i.e., cy40, on which AROME is based; IFS is jointly developed by ECMWF and MétéoFrance; and ' $t$ ' refers to the model release specific to Météo-France, i.e., Toulouse; finally 1 refers to the release number).

The analyses of AROME/HU forecasts are updated three hourly at $0,3,6,9$, $12,15,18$, and 21 UTC. The AROME/HU 3D-Var system uses only conventional observations from ground-based synoptic stations (SYNOP), radiosondes (TEMP), zenith total delays (GNSS ZTD), and aircraft data (AMDAR and MRAR). The assimilated observations, meteorological parameters, and the date of their operational implementations are summarized in Table 1. Most of the observations (except for GNSS ZTD) are routinely received and preprocessed in OPLACE (Observation Preprocessing system of RC LACE) hosted by the Hungarian Meteorological Service (Trojáková et al., 2019).

Table 1: Assimilated observation types and parameters in AROME/HU operational system

\begin{tabular}{lll}
\hline \hline Observation type & Parameter & Date of Operational implementation \\
\hline \hline SYNOP & $\mathrm{u}, \mathrm{v}, \mathrm{T} 2 \mathrm{M}, \mathrm{HU} 2 \mathrm{M}, \mathrm{z}$ & March 2013 \\
TEMP & $\mathrm{u}, \mathrm{v}, \mathrm{T}, \mathrm{q}, \mathrm{z}$ & March 2013 \\
AMDAR & $\mathrm{u}, \mathrm{v}, \mathrm{T}, \mathrm{q}$ & March 2013 (u, v, T) November 2016 (q) \\
Slovenian / Czech Mode-S MRAR & $\mathrm{u}, \mathrm{v}, \mathrm{T}$ & November 2016 / March 2021 \\
GNSS & ZTD & September 2018 \\
\hline
\end{tabular}

In our local data assimilation system, two kinds of analyses are prepared and distinguished based on the length of cut-off time: short cut-off and long cut-off (Bölöni, 2006). This is the time interval of observations collection for data 
assimilation. The aim of using short cut-off analysis is to provide initial conditions for operational model prediction as quickly as possible. The long cut-off analysis is prepared later for the same network time with longer waiting time for the observations, this analysis is used as an initial condition for the next first guess. In the recent AROME/HU version, this short cut-off time is set to +/- 90 minutes.

The operational AROME/HU version runs 8 times a day and provides forecasts up to 48 hours for main terms $(0,6,12$, and 18 UTC) and 36 hours for additional terms $(3,9,15$, and $21 \mathrm{UTC})$.

\section{Surface data assimilation developments in AROME/HU model}

\subsection{Optimal interpolation}

In the IFS/ARPEGE/ALADIN model family, the optimal interpolation method has been used for data assimilation purposes for a long time. Meanwhile, the variational assimilation scheme became paramount for upper-air DA allowing the use of remote-sensing observations, however, the OI approach is still employed for surface analysis by many operational centers. The land surface assimilation based on OI consists of the quality control of conventional observations, the $2 \mathrm{~m}$ analysis of temperature and relative humidity, and the corresponding correction of surface parameters using $2 \mathrm{~m}$ increments (Giard and Bazile, 2000). For the $2 \mathrm{~m}$ analysis, the OI method solves the analysis equation for each grid point individually assuming that only a limited number of observations influences one grid-point. The correction of surface parameters is done differently in ALADIN and AROME models because of the applied different surface parametrization schemes. In ALADIN model, the so-called ISBA (Interaction Soil Biosphere Atmosphere) scheme (Noilhan and Planton, 1989; Noilhan and Mahfouf, 1996) is used, while in AROME model, a more advanced, i.e., an externalized surface scheme is utilized, which is called SURFEX (Masson et al., 2013).

The first local DA system in AROME was introduced operationally with variational upper-air data assimilation replacing the former downscaled ALADIN initial conditions (Bölöni, 2006; Mile et al., 2015). Although the downscaling procedure remained for the AROME surface initialization, the use of ALADIN surface analyses continued. Such a dependence on the ALADIN system was not optimal in an operational AROME system, therefore, the experimentation of AROME surface DA using the OI method (OI-main) was started as well. Various observing system experiments have been carried out for the summer and winter seasons and different weather situations. Verification results revealed that the operational configuration with downscaled ALADIN surface has usually wet and cold bias in AROME near-surface forecast parameters, while with OI-main, AROME shifted towards the dry and warm bias changing slightly the diurnal cycle of surface parameters during the first $24 \mathrm{~h}$ of the model forecast (not shown). Moreover, the verification of precipitation forecasts with AROME OI-main 
surface analysis showed mostly positive impact in particular case studies (summer and winter) and a short summer period as well (Fig. 1). After six months of surface spin-up, the AROME surface assimilation with OI-main became operational in 2016.

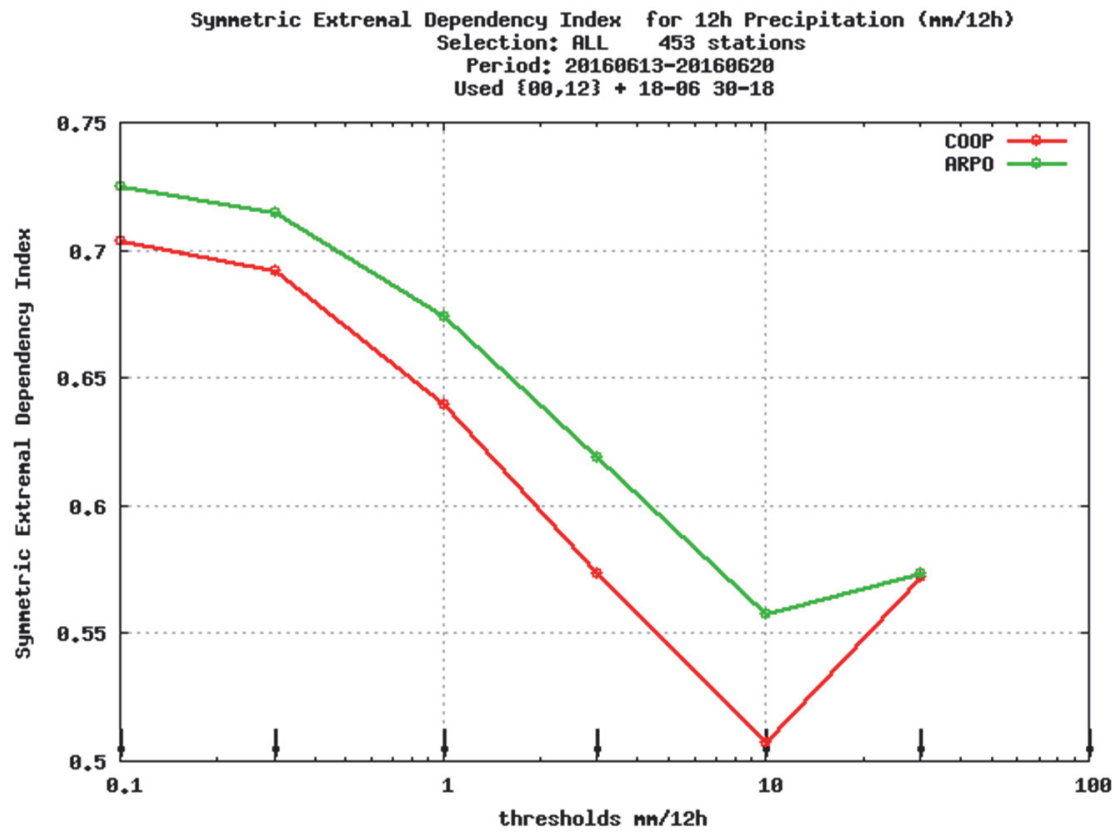

Fig. 1. Symmetric extremal dependency index (SEDI) verification skill score for $12 \mathrm{~h}$ accumulated precipitation forecast comparing AROME operational (COOP) system without surface data assimilation and with AROME experiment using OI-main surface data assimilation (ARPO). Verification against conventional SYNOP observations (period June 13 to 20,2016$)$.

\subsection{Simplified extended Kalman filter}

The exact initialization of the soil variables is a very crucial point to provide precise numerical weather prediction (NWP) forecasts. Inaccurate soil moisture content and soil temperature can lead to significant forecast errors of the screenlevel atmospheric variables, $2 \mathrm{~m}$ air temperature (T2M), and $2 \mathrm{~m}$ relative humidity (HU2M) (Hess, 2001). Several methods have been developed to minimize errors in soil parameters. In this study, SEKF proposed by Mahfouf et al. (2009) is tested using AROME/HU cy43t2. SEKF allows assimilation of both conventional (screen-level) and non-conventional (satellite) observations to produce surface analysis. ASCAT soil moisture and SPOT/VGT leaf area index (LAI) nonconventional satellite observations were assimilated by several authors (Barbu et al., 2014; Albergel et al., 2017; Rüdiger et al., 2010). These studies demonstrated the benefit of joint assimilation of soil moisture and LAI by using the multi-patch 
version of SURFEX. It was shown, that the assimilation worked effectively, but the impact of the assimilation on the vegetation phenology and the water and carbon fluxes varied from season to season.

In EKF, dynamically changing coefficients are used, and the analysis is obtained as:

$$
\begin{aligned}
x_{a} & =x_{b}+\mathbf{K}\left(y-\mathcal{H} x_{b}\right), \\
\mathbf{K} & =\mathbf{B H}^{\mathbf{T}}\left(\mathbf{H B H}^{\mathbf{T}}+\mathbf{R}\right),
\end{aligned}
$$

where $x_{a}$ is the analysis (so-called control variables: TG1, TG2, WG1, WG2), $x_{b}$ is the result of a previous model run, $y$ is the observation (T2M, HU2M), $\mathcal{H}$ is the non-linear observation operator, which transforms control variables from model space into observation space. $\mathbf{H}$ matrix is the linearized observation operator, $\mathbf{K}$ is the Kalman-gain matrix that represents the relative importance of the error of the observation concerning the prior estimate. $\mathbf{B}$ and $\mathbf{R}$ are the covariance matrices of the background errors and the observation errors, respectively. In this study, the simplified version of the EKF, namely SEKF is used, meaning the background covariance matrix $\mathbf{B}$ does not evolve with time. The elements of $\mathbf{H}$ (called Jacobian matrix), are calculated by finite differences. Perturbing each component $\left(x_{j}\right)$ of the control vector $\mathbf{x}$, the elements of matrix $\mathbf{H}$ are composed for each integration $i$ :

$$
\mathbf{H}_{i j}=\frac{\partial y_{i}}{\partial x_{j}} .
$$

In this study, SEKF is used as control vectors of the water contents and temperatures of two soil layers (superficial (WG1, TG1) and root-zone (WG2, TG2)) propagated by SURFEX three-layer soil scheme (superficial $0-1 \mathrm{~cm}$, root zone 0-2 $\mathrm{m}$, and deep soil 2-3 m). The observation terms are screen-level T2M and HU2M. The Jacobian matrix is the following:

$$
\mathbf{H}=\begin{array}{ccrc}
\frac{\partial T 2 M}{\partial T G 1} & \frac{\partial T 2 M}{\partial T G 2} & \frac{\partial T 2 M}{\partial W G 1} & \frac{\partial T 2 M}{\partial W G 2} \\
\frac{\partial H U 2 M}{\partial T G 1} & \frac{\partial H U 2 M}{\partial T G 2} & \frac{\partial H U 2 M}{\partial W G 1} & \frac{\partial H U 2 M}{\partial W G 2}
\end{array} .
$$

The small perturbations (with magnitude $10^{-3}$ or less) lead to a good approximation of the linear behavior (Mahfouf, 2009), and the Jacobian perturbations are assigned $10^{-4}$ for the soil water content and $10^{-5}$ for the soil temperature in our configurations. The assimilation window is set to 3 hours. In the analysis cycle, SURFEX is run several times, firstly to get the reference forecast, then the perturbed runs of the control variables. 
In this study, a test run was performed and validated. The experiment lasted from July 9 to 31, 2020 (starting with a 2-week spin up period from June 25, 2020). Forcing files were required for offline SURFEX runs (i.e., radiation, precipitation, wind, humidity, temperature, and pressure), which were coming from AROME/HU inline forecasts. The wind, humidity, temperature, and pressure values correspond to the lowest model level of AROME/HU, which is currently $9 \mathrm{~m}$.

Pointwise verification was executed for both periods against SYNOP and TEMP observations. The verification of $2 \mathrm{~m}$ temperature forecasts shows a large improvement for the nighttime hours with SEKF, and the large warm bias during the nights was reduced considerably (Fig. 2). SEKF was able to improve the $2 \mathrm{~m}$ temperature analysis throughout the whole period (Fig. 3, left). However, its daytime forecasts over Hungary do not differ significantly from the OI-main ones (Fig. 3, right).

0 UTC runs

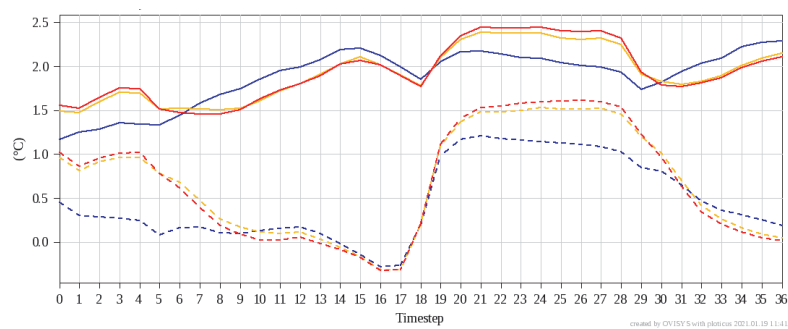

12 UTC runs

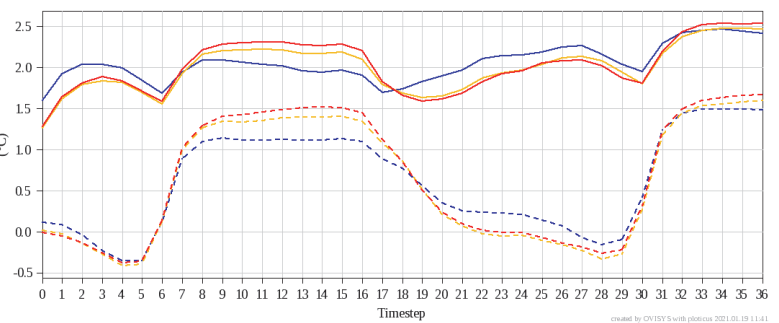

Fig 2. Bias (dashed line) and RMSE (solid line) of $2 \mathrm{~m}$ temperature forecasts in the 0 and 12 UTC runs from July 9 to 31, 2020. Blue: cy43 with SEKF, orange: cy43 with OI-main, red: cy40 with OI-main.

Analysis and observation

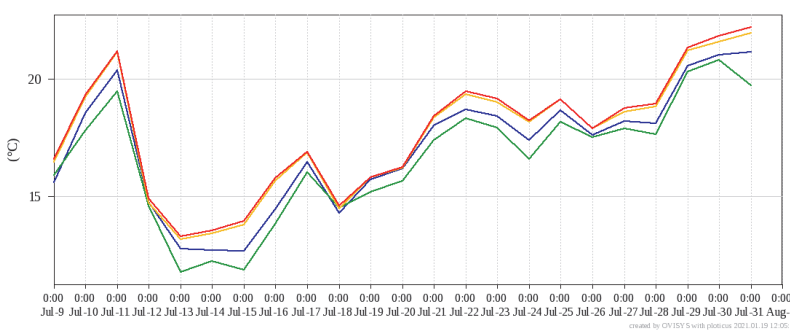

12-hour forecast and observation

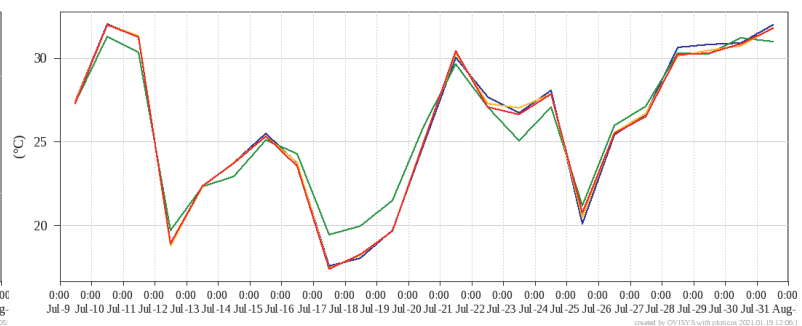

Fig. 3. Evolution of $2 \mathrm{~m}$ temperature analysis and 12-hour forecast in the 0 UTC runs and observations (green) from July 9 to 31, 2020. Blue: cy43 with SEKF, orange: cy43 with OI-main, red: cy40 with OI-main. 
July 2020 had warm and overall rainy weather in the Carpathian Basin, where spatiotemporal distribution of precipitation was extreme. It is a typical problem in AROME/HU that the minimum temperature is usually overestimated and the maximum temperature is underestimated in the dry and warm anticyclonic periods. The case study of July 15, 2020 indicates that the $2 \mathrm{~m}$ temperature analysis was inaccurate using OI-main (Fig. 4, right). More accurate analysis was provided by SEKF, especially in the central part of the country (Fig. 4, middle). At the same time, the 12-hour forecast of SEKF resulted in an unrealistic warm pattern over the south part of the domain (Fig. 5, middle).
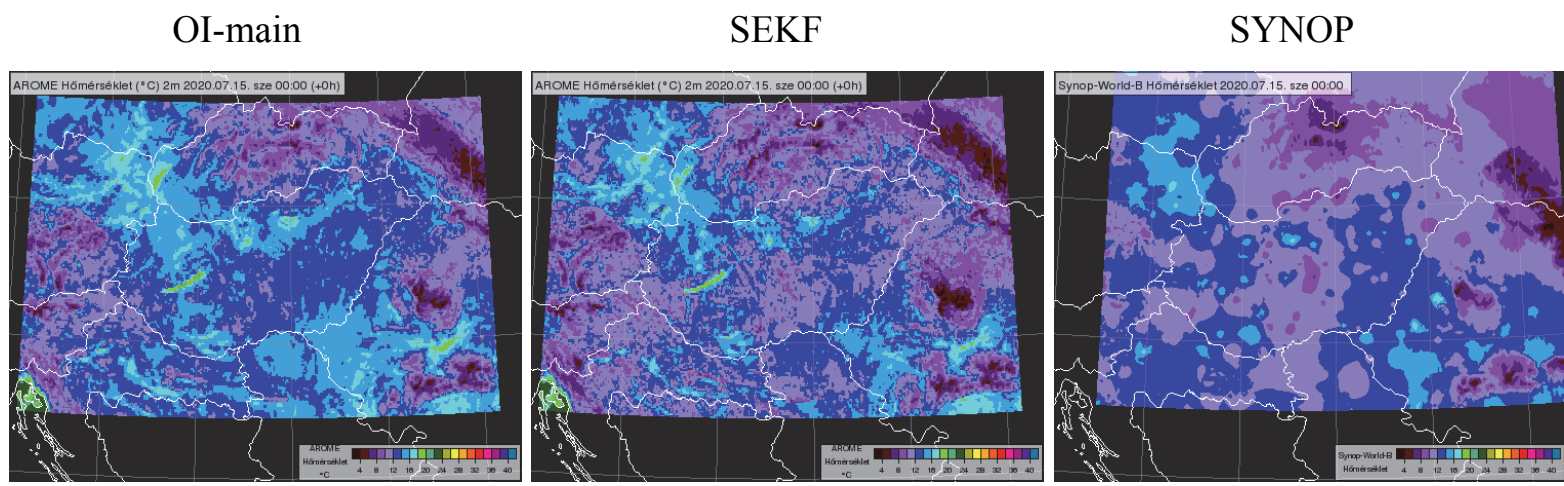

Fig. 4. $2 \mathrm{~m}$ temperature analysis in AROME/HU cy43 with OI-main and SEKF, observations at 0 UTC on July 15, 2020.

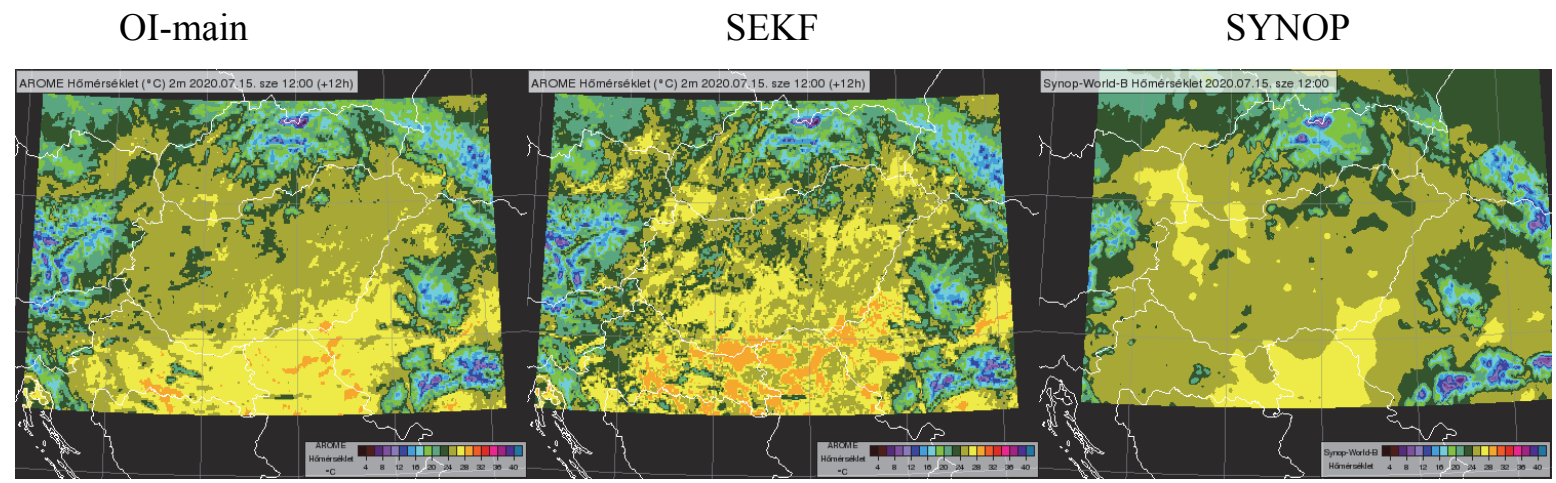

Fig. 5. 12-hour forecast of $2 \mathrm{~m}$ temperature in AROME/HU cy43 with OI-main and SEKF, observations at 12 UTC on July 15, 2020.

SEKF produced very dry soil in comparison with OI-main (Fig. 6). This issue is able to generate the above mentioned $2 \mathrm{~m}$ temperature overestimation in the south during the day. 
OI-main

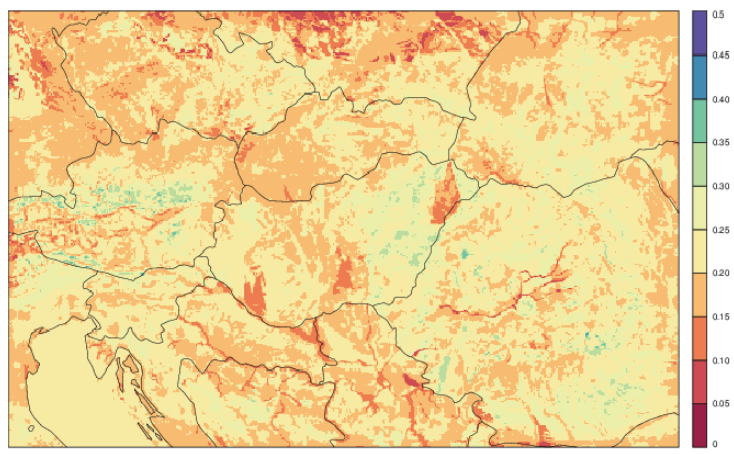

SEKF

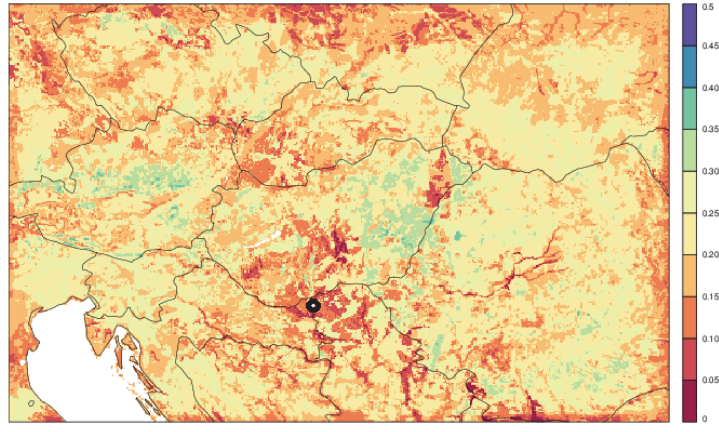

Fig. 6. Root-zone soil moisture (WG2) analysis at 0 UTC on 15 July, 2020 for OI-main and SEKF.

The evolution of WG2 analysis can be seen in Fig. 7 for a given point marked with a black circle in Fig. 6 . The soil moisture content decreased very rapidly by using SEKF, however, OI-main did not change drastically the soil moisture values. The main soil texture is sand $(73 \%)$ in this area, so the soil moisture reflects immediately on the variability of the precipitation.

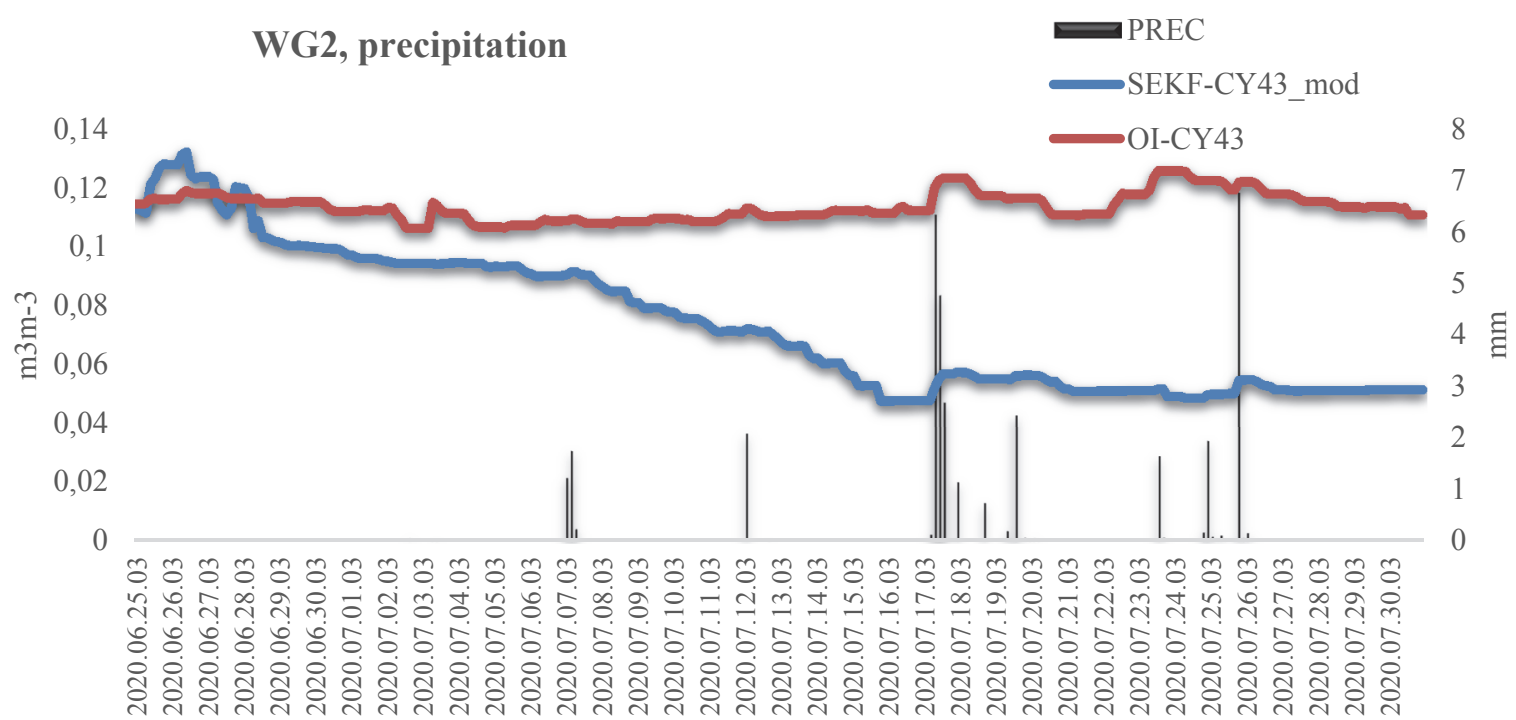

Fig. 7. Evolution of soil moisture (WG2) and precipitation (black) for SEKF (blue) and OI-main (red). 
Fig. 8 shows analysis minus guess (A-G) increments for soil temperature and soil moisture in different analysis times summed for the whole period and all grid points over the domain. The TG2 increment is bigger for the nighttime and smaller for the daytime periods in the case of SEKF. For OI-main the TG2 increments are small and consistent. In contrast, the WG2 increments are large for daytime and smaller for nighttime for both methods. The WG2 increments are similar and comparable with each other.

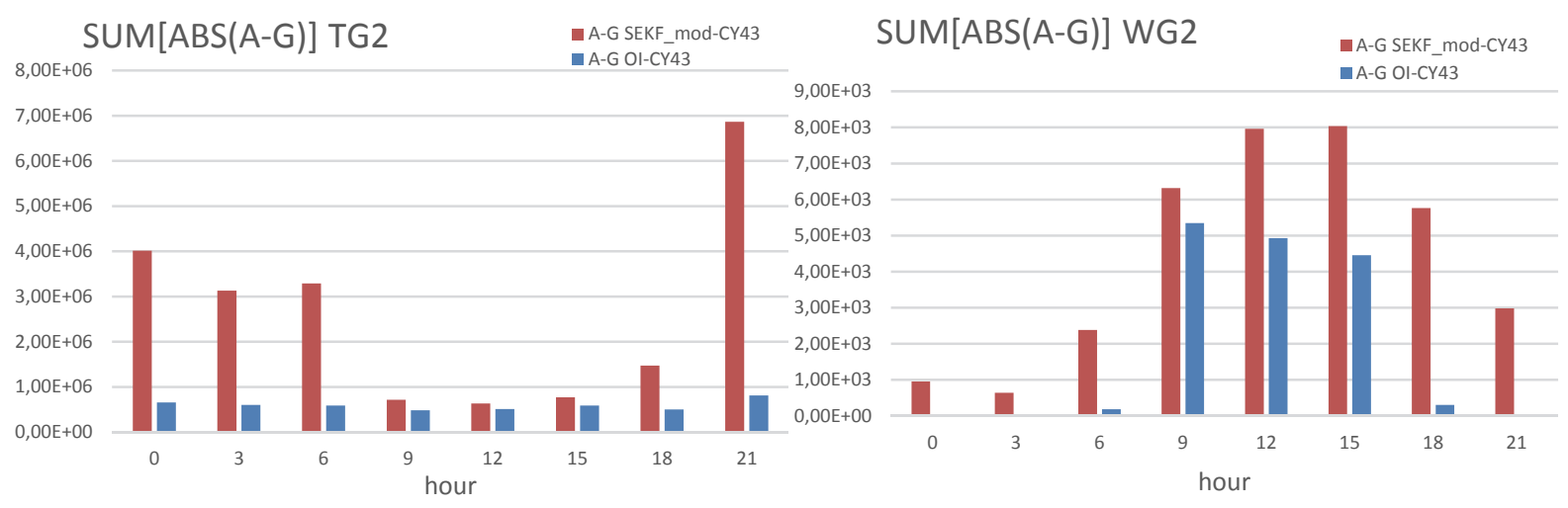

Fig. 8. Soil temperature (TG2) and soil moisture (WG2) increments for all of the grid points over the domain from July 9 to 31, 2020 for SEKF (blue) and OI-main (red).

To conclude, SEKF provides a positive impact on the analyses and the shortrange forecasts as well. However, further investigations are still needed to find the best possible combination of the assimilation parameters, like observation, background errors, and the perturbation size of the Jacobians.

\section{Upper-air data assimilation developments in AROME/HU model}

\subsection{Investigation of rapid update cycle}

The main goal of the rapid update cycling (RUC) approach is to employ more observations with reduced representation error in time, which would serve as a basis for the enhancement of data assimilation by including radar data assimilation soon (Mile et al., 2015). This study was carried out with AROME/HU cy40t1 with different assimilation window lengths. The cut-off time in the case of RUC was reduced to 30 minutes instead of 90 minutes, which is used in the operational 3hourly updated DA cycle.

In this study, two 30-day test periods had been chosen. The first was a winter period covering all days between January 8 and February 6, 2017. The second period was a spring period from May 4 to June 2, 2019, including numerous 
convective events inside the model domain. Each model run had started at 0,6 , 12 , and 18 UTC analyses and performed 12-hour forecasts. The assimilation cycle was started six days earlier than the first long forecast to provide an appropriate first guess field for the beginning of the experiments. Some modifications were made in the configuration settings, e.g., the assimilation cycle frequency was set to 1 hour and the cut-off time was shrunk to +/-30 minutes accordingly. Meanwhile, the surface assimilation cycle frequency was set to be adjustable, i.e., in these experiments 1-, 3-, and 6-hourly updated surface data assimilation were applied. In the last two experimental setups, (called AROME_combo_1hourly_surf3, and AROME_combo_lhourly_surf6 hereafter), the asynoptic surface analyses were initialized from previous model forecasts without taking into account surface observations. The following four configurations were tested for both periods:

- AROME_3hourly represents the original settings of operational AROME/HU;

- AROME_lhourly represents 1-hourly DA cycle for 3D-Var and surface data;

- AROME_combo_lhourly_surf3 consists of a combination of 1-hourly updated upper-air assimilation cycle with 3D-Var and 3-hourly updated surface assimilation cycles with surface data;

- AROME_combo_lhourly_surf6 is the same as AROME_combo_lhourly_$\operatorname{surf} 3$ but the surface assimilation is updated every 6 hours.

To evaluate the results provided by four configurations, two different verification approaches were applied. Standard verification methods (RMSE, bias) were used for $2 \mathrm{~m}$ temperature forecasts (Figs. 9-10), and SAL verification method was used for precipitation in the spring case. SAL verification method provides an objective quality measure for forecasted precipitation fields compared to radar observations as three distinct components are used, namely structure, amplitude, and location (Wernli et al., 2008). In order to get a comprehensive picture of all three components, the central statistic approach was applied (Table 2). Better performing cases are closer to the center, therefore, a given percentage of cases $(5 \%, 10 \%, 20 \%$, and $50 \%)$ can be covered by a shorter radius.

The results suggest that AROME_lhourly performs better than AROME_3hourly in the case of $2 \mathrm{~m}$ temperature and dew point temperature. Higher accuracy was provided by reduction of surface assimilation cycle frequency (AROME_combo_lhourly_surf3, AROME_combo_lhourly_surf6).

Meanwhile, considering precipitation, there is no significant difference between the configurations as SAL verification shows balanced performance for each setting (Table 2). 


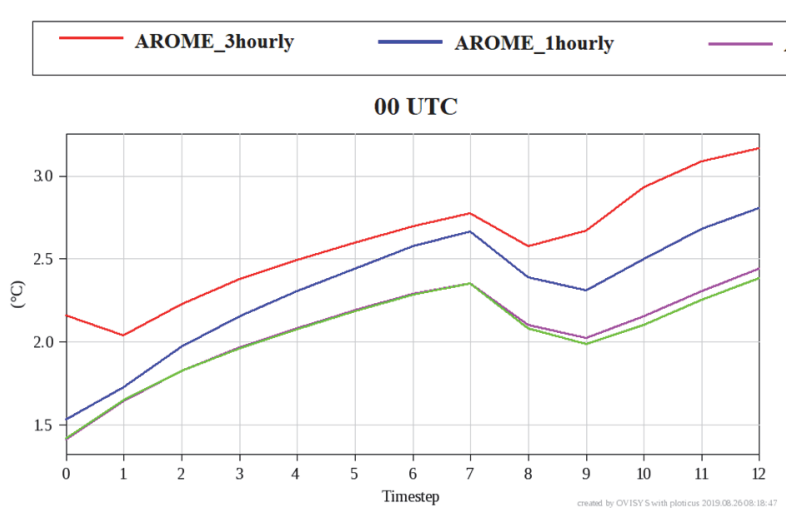

12 UTC

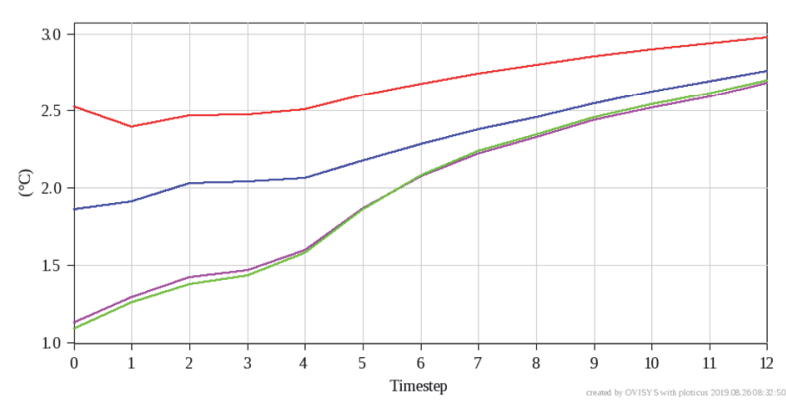

AROME_combo_1hourly_surf3 $\quad$ AROME_combo_1hourly_surf6

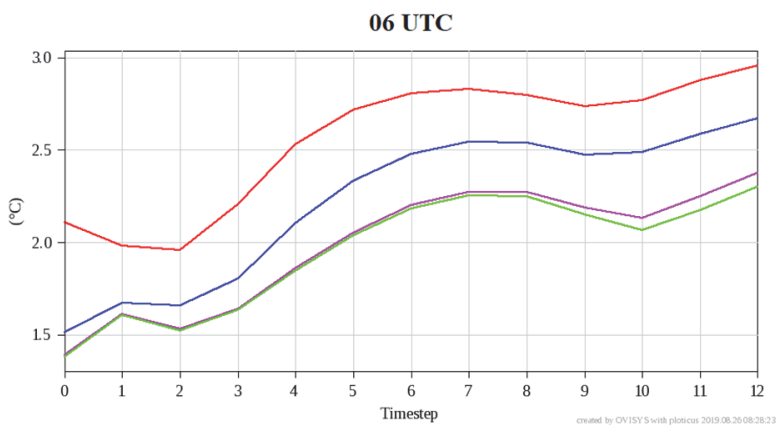

18 UTC

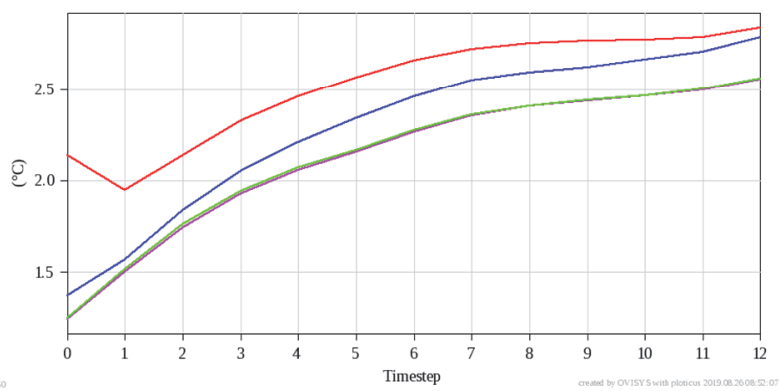

Fig. 9. RMSE of $2 \mathrm{~m}$ temperature for each configuration in the function of lead-time in the winter period.

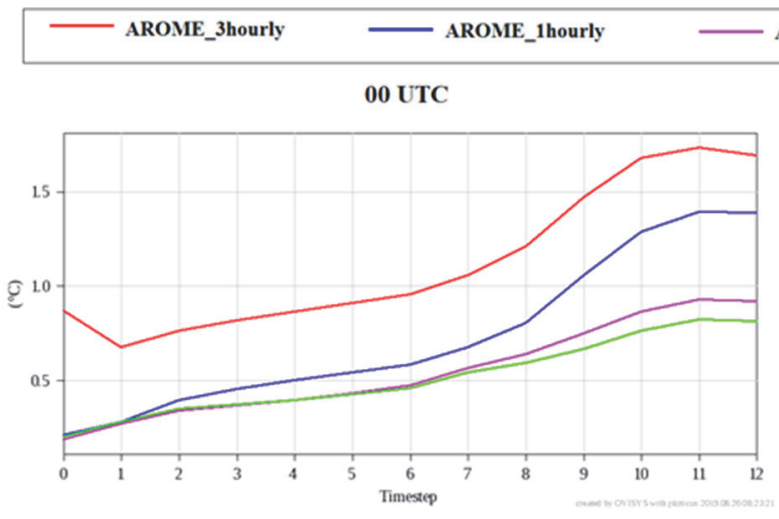

12 UTC

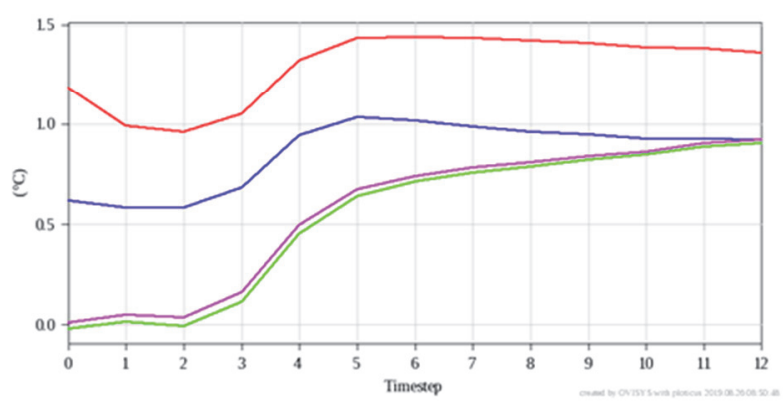

AROME_combo_1hourly_surf3 — AROME_combo_1hourly_surf6 06 UTC

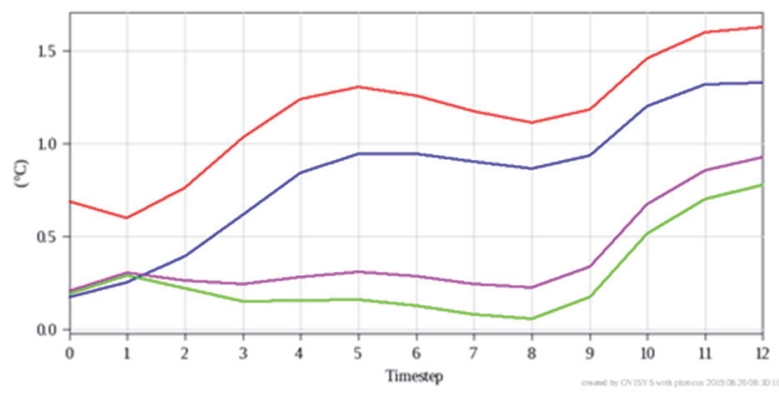

18 UTC

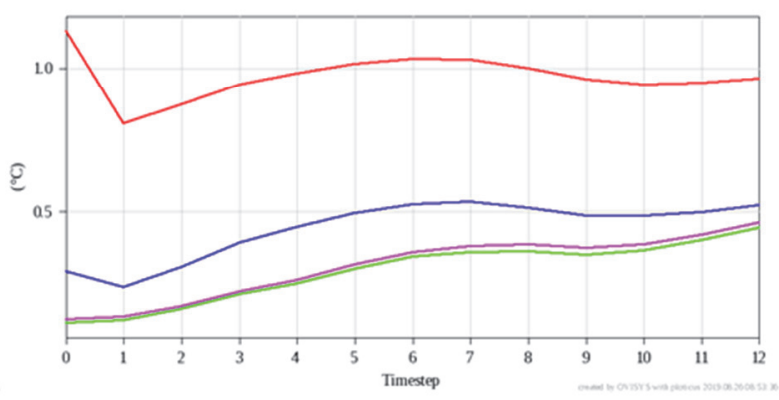

Fig 10. Bias of $2 \mathrm{~m}$ temperature for each configurations in function of lead-time in winter period. 
Table 2: SAL results of each configuration for spring case. Lower radius values indicate better performance on precipitation forecasts. Green cells represent the best performance, redcells respresent the worst.

\begin{tabular}{|l|c|c|c|c|c|c|c|c|}
\hline & \multicolumn{3}{|c|}{$\mathbf{0 0}$ UTC } & \multicolumn{3}{c|}{ 06 UTC } \\
\hline & $\mathbf{5 \%}$ & $\mathbf{1 0 \%}$ & $\mathbf{2 0 \%}$ & $\mathbf{5 0 \%}$ & $\mathbf{5 \%}$ & $\mathbf{1 0 \%}$ & $\mathbf{2 0 \%}$ & $\mathbf{5 0 \%}$ \\
\hline AROME_3hourly & 0.282 & 0.391 & 0.570 & 0.992 & 0.382 & 0.475 & 0.666 & 1.037 \\
\hline AROME_1hourly & 0.276 & 0.365 & 0.506 & 1.075 & 0.297 & 0.454 & 0.666 & 1.026 \\
\hline AROME_combo_1hourly_surf3 & 0.274 & 0.373 & 0.578 & 1.117 & 0.325 & 0.492 & 0.652 & 1.051 \\
\hline AROME_combo_1hourly_surf6 & 0.261 & 0.410 & 0.570 & 1.128 & 0.369 & 0.484 & 0.655 & 1.016 \\
\hline & \multicolumn{7}{|c|}{$\mathbf{1 2}$ UTC } & \multicolumn{4}{|c|}{$\mathbf{1 8}$ UTC } \\
\hline & $\mathbf{5 \%}$ & $\mathbf{1 0 \%}$ & $\mathbf{2 0 \%}$ & $\mathbf{5 0 \%}$ & $\mathbf{5 \%}$ & $\mathbf{1 0 \%}$ & $\mathbf{2 0 \%}$ & $\mathbf{5 0 \%}$ \\
\hline AROME-3hourly & 0.366 & 0.447 & 0.665 & 1.096 & 0.357 & 0.534 & 0.684 & 1.157 \\
\hline AROME-1hourly & 0.358 & 0.450 & 0.625 & 1.052 & 0.379 & 0.514 & 0.768 & 1.216 \\
\hline AROME-1hourly_surf3 & 0.307 & 0.424 & 0.648 & 1.094 & 0.369 & 0.484 & 0.643 & 1.159 \\
\hline AROME-1hourly_surf6 & 0.302 & 0.442 & 0.647 & 1.111 & 0.314 & 0.446 & 0.642 & 1.216 \\
\hline
\end{tabular}

The biggest difference between the configurations can be seen on January 29, 2017. AROME_3hourly has more than five degrees Celsius RMSE, but AROME_combo_lhourly_surf3 and surf6 have only around one degree Celsius RMSE (Fig. 11). On this particular day (Fig. 12), the big difference in the RMSE, in favor of $A R O M E \_c o m b o \_s u r f 3$ can be explained by the lack of cloud cover in AROME_3hourly and AROME_lhourly (Fig. 13). This usually happens in the Carpathian Basin when low-level clouds develop and remain during wintertime. In this situation, the NWP models usually are not able to serve accurate forecasts.

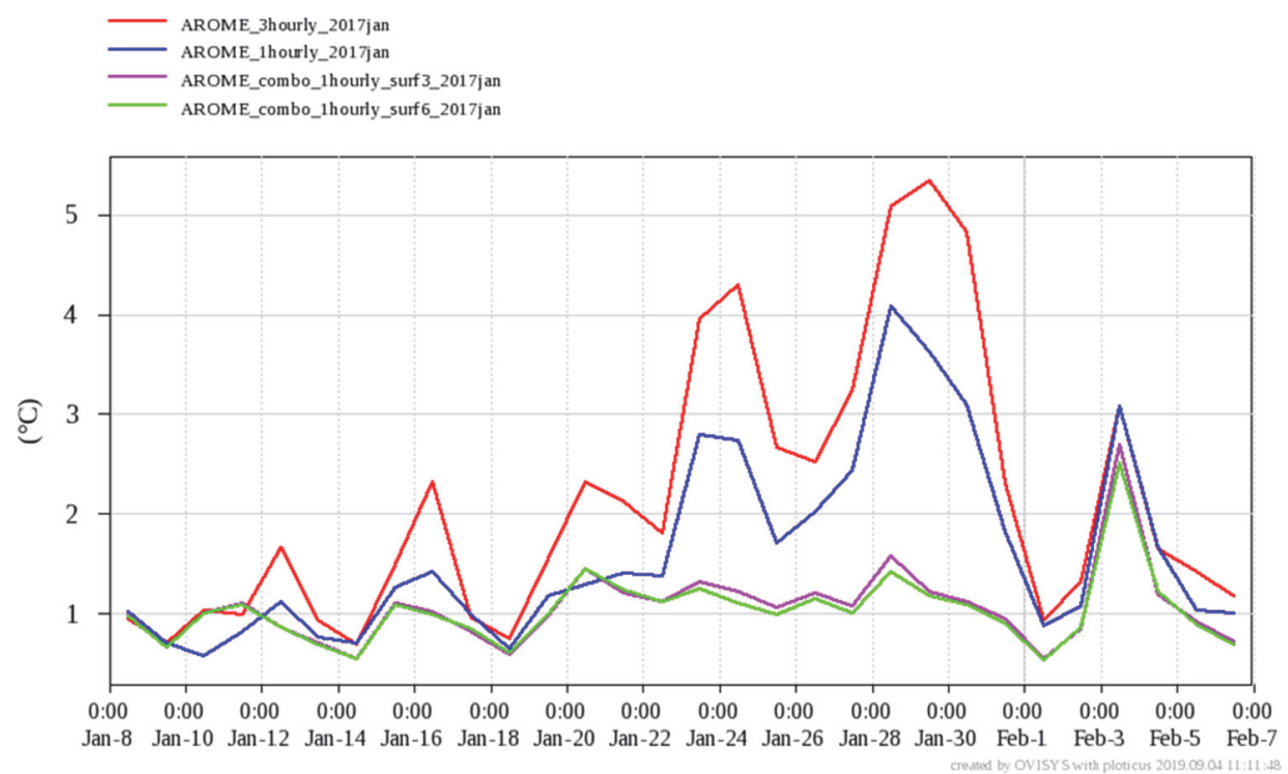

Fig. 11. RMSE of $2 \mathrm{~m}$ temperature for $12 \mathrm{UTC}$ runs at 0 time step. 


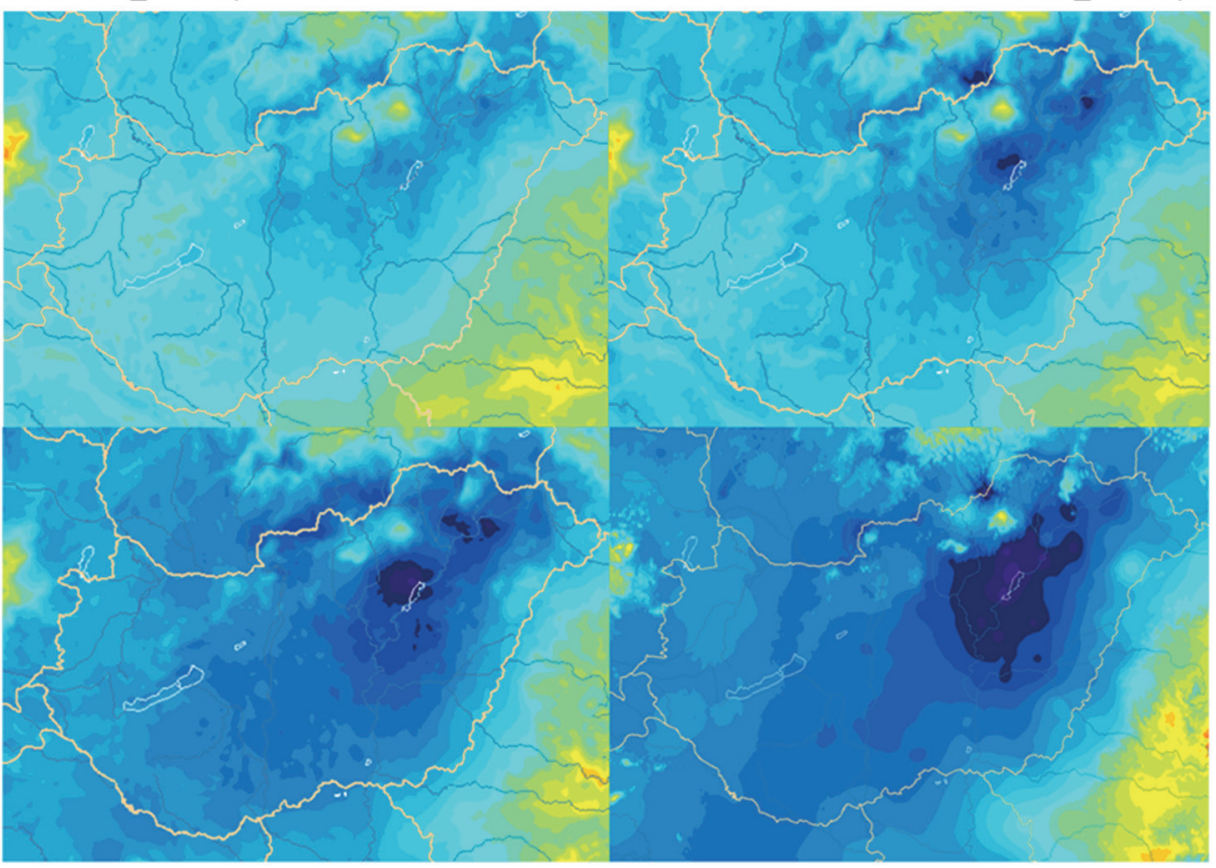

AROME_combo_1hourly_surf3

SYNOP mesurments

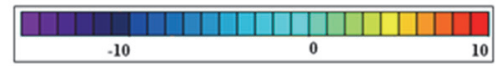

Fig. 12. Temperature fields provided by different configurations comparing to measurements at 12 UTC, on January 29, 2017.

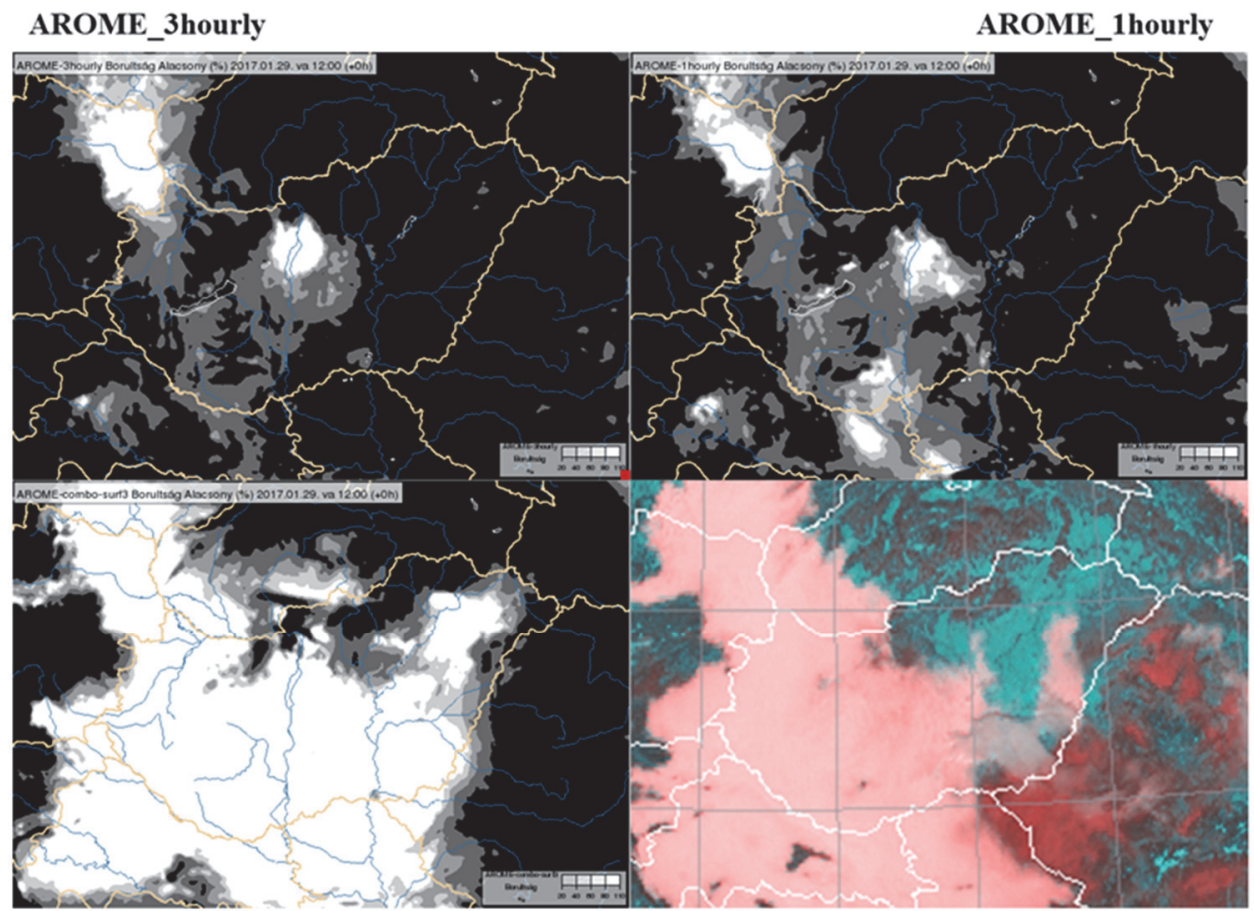

AROME_combo_1hourly_surf3

MSG HRV Composite

Fig. 13. Cloud cover fields provided by different configurations comparing to satellite observation at 12 UTC, on January 29, 2017. 
Further examination was performed with increments of soil temperature (TG1, TG2) and soil moisture (WG1, WG2) in order to get a clear picture of the unexpected behavior of the model. The increments and soil variables were examined from January 18 to 31, 2017. Soil temperature increments looked normal, however, soil moisture increments were 0 during the whole period (not shown). This means, that the soil moisture was driven by the model only, no actual correction by the assimilation was performed, meanwhile, all configurations yielded different soil moisture contents. Further investigation is necessary to get the final conclusions.

\subsection{Impact of Aircraft Mode-S MRAR data in AROME/HU}

High resolution and high-density aircraft data are important and unmissable to improve the data assimilation system. Mode-S MRAR data can be used similarly to conventional AMDAR data and have similar quality as well. They are gathered through interrogation of suitable aircraft using specific (Mode-S TAR) radars, which means that only aircraft equipped with Mode-S transponders is able to return meteorological data. Smaller fraction of aircrafts is equipped for MRAR data, which contains specific meteorological parameters, like temperature and wind, but this relatively small amount of data is extremely valuable for data assimilation, as it contains meteorological data of similar quality as that of AMDAR data (Strajnar, 2012).

For the AROME/HU model, Slovenian Mode-S MRAR data was the first available for assimilation purposes. These observations are disseminated through the common preprocessing platform OPLACE (Trojáková et al., 2019) since 2015. The first experiments in Hungary have started in the following year. In a case study, improved precipitation fields were experienced, and over a longer period, results showed mainly neutral impact with some improvement in the bias of wind gust and ETS score of precipitation. These data were introduced operationally at the end of 2016. Since 2019, Mode-S MRAR data from the Czech Republic are also available in OPLACE, which are also ready for assimilation. In case of Hungarian measurements, the air traffic control provided raw data, which has to be preprocessed in the first step. Fig. 14 shows the area covered by the various Mode-S data. 


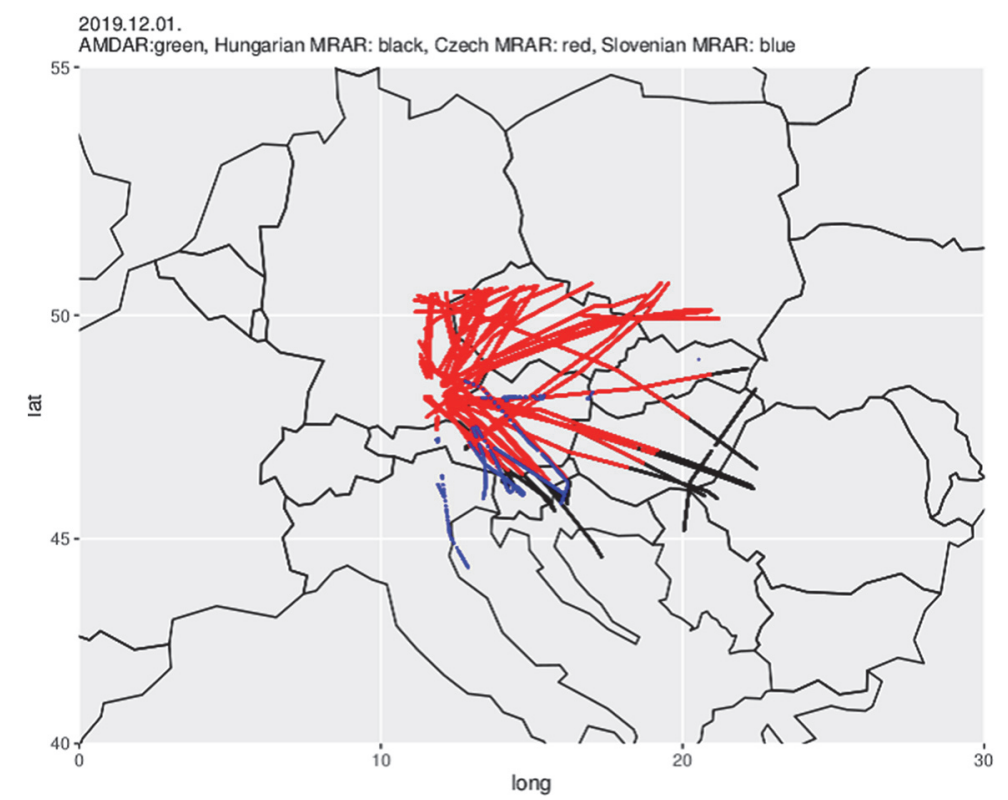

Fig. 14. Mode-S data collected by the Czech (red), Hungarian (black), and Slovenian (blue) radars over the AROME/HU domain.

\subsubsection{Impact of Czech Mode-S data in AROME/HU}

Two experiments were carried out to investigate the impact of Czech Mode-S MRAR data assimilation on the quality of the forecast. The first experiment covered a winter period (December 1 to 19,2019), while the second one covered a summer period (June 1 to 30, 2020). Both experiments were based on the operational AROME/HU and the only difference was the inclusion of Czech Mode-S data, obtained from the OPLACE server. The two experiments differ from each other in regards to the forecast length ( 24 and 36 hours for the winter and summer periods, respectively) and the run hours $(0,6,12$, and 18 UTC runs in the winter experiment, and 0, 9, and 12 UTC runs in the summer experiment).

Observation monitoring shows that only a small fraction of the total number of Czech Mode-S data is active in the experiments (Fig. 15), which is likely due to the horizontal thinning. In the case of the winter experiment, the number of active Czech Mode-S data is very similar to the number of AMDAR data, which makes a reasonable comparison of their impact. In the case of the summer experiment, however, the number of Czech Mode-S observations is extremely low (Fig. 15), including several days with zero observations. This probably indicates the severe effect of the COVID-19 pandemic on the number of flights, and makes it much more difficult to evaluate the summer experiment.

It can be concluded that the assimilation of Czech Mode-S data improves slightly the forecast skill of AROME/HU. Fig. 15 shows that the impact of the Mode-S dataset was quite substantial for specific days, at least for the summer period, but the difference is usually much smaller. 

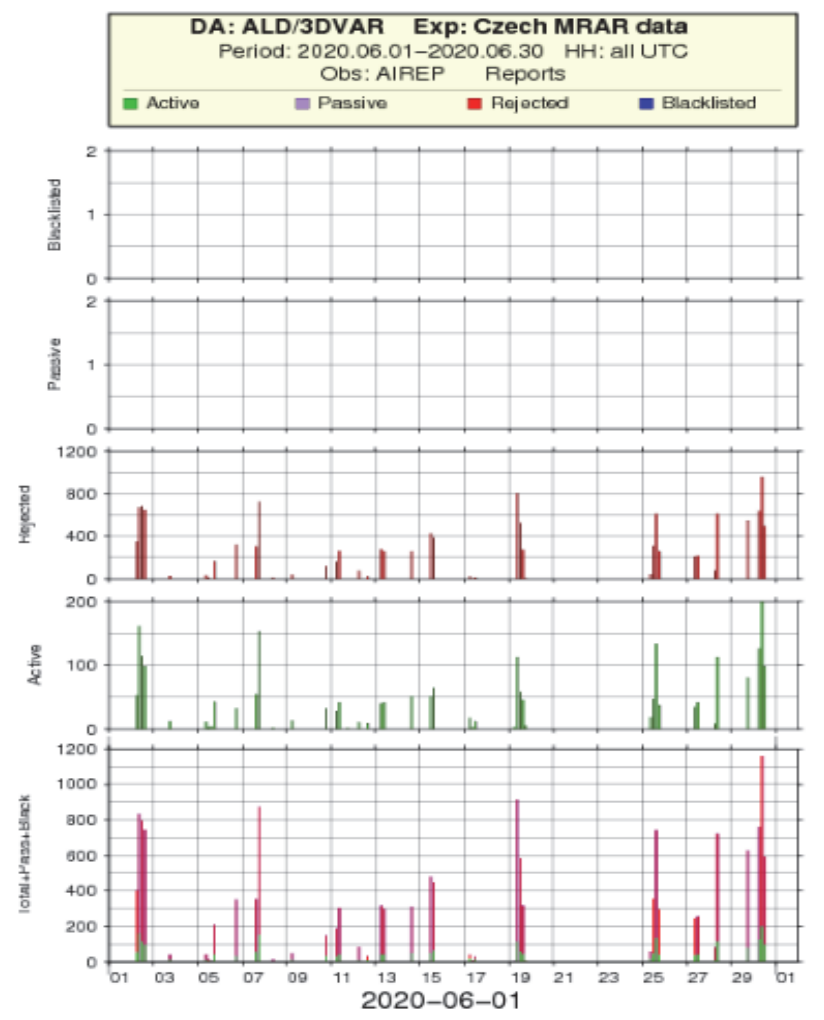

Fig. 15. Number of Czech Mode-S MRAR data over the AROME/HU domain for the summer (left) and the winter (right) experiment. Green and red columns represent the active and rejected observations, respectively.

Pointwise verification was performed for both periods against SYNOP and TEMP observations. The verification results show small improvement for the winter period, when scores are usually very close to the operational ones, although a slight improvement can be detected in most of the cases. A remarkable, albeit small positive impact can be seen in precipitation forecasts (Fig. 16).

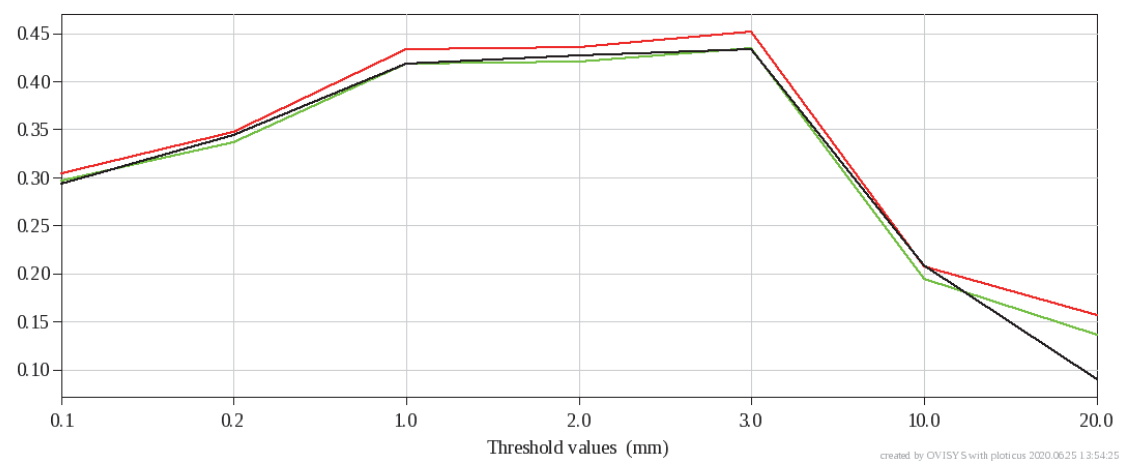

Fig. 16. ETS score of 12-hour accumulated precipitation in the 18 UTC runs from December 1 to 19, 2019. Red line: experiment with Czech Mode-S data, black line: experiment with Hungarian Mode-S data, green line: reference experiment without any Mode-S data. 
For the summer period, the results are more varied, and show greater differences compared to the ones seen in the winter period. This can be attributed to the fact that there was a much greater amount of precipitation in the summer period. A case study of a convective event also shows that in specific cases, the inclusion of Mode-S data can significantly improve the precipitation forecast, especially regarding the spatial distribution of the amount of precipitation (Fig. 17). Verification scores are overall neutral, but in some cases, a significant improvement was obtained, especially for precipitation (Fig. 18). Other surface variables, however, show little or no improvement (not shown), therefore, the results are quite similar to the ones seen in the winter experiment.

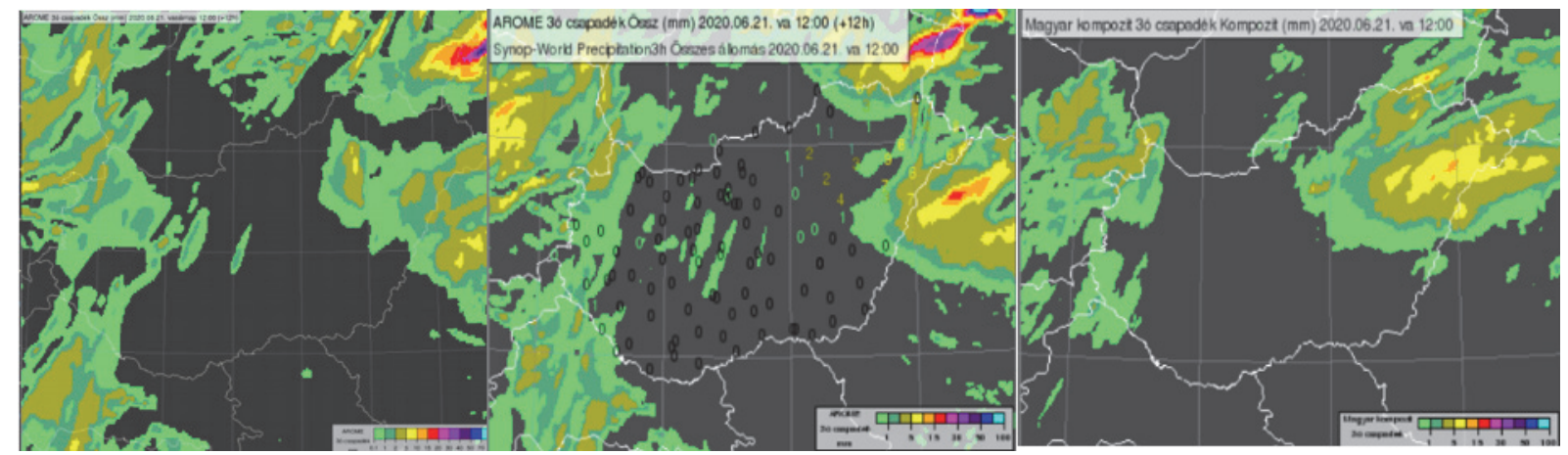

Fig. 17. 3-hour precipitation forecast of the experiment using Mode-S data (left), reference run (middle), and the observed precipitation (right) at 12 UTC, on June 21, 2020.

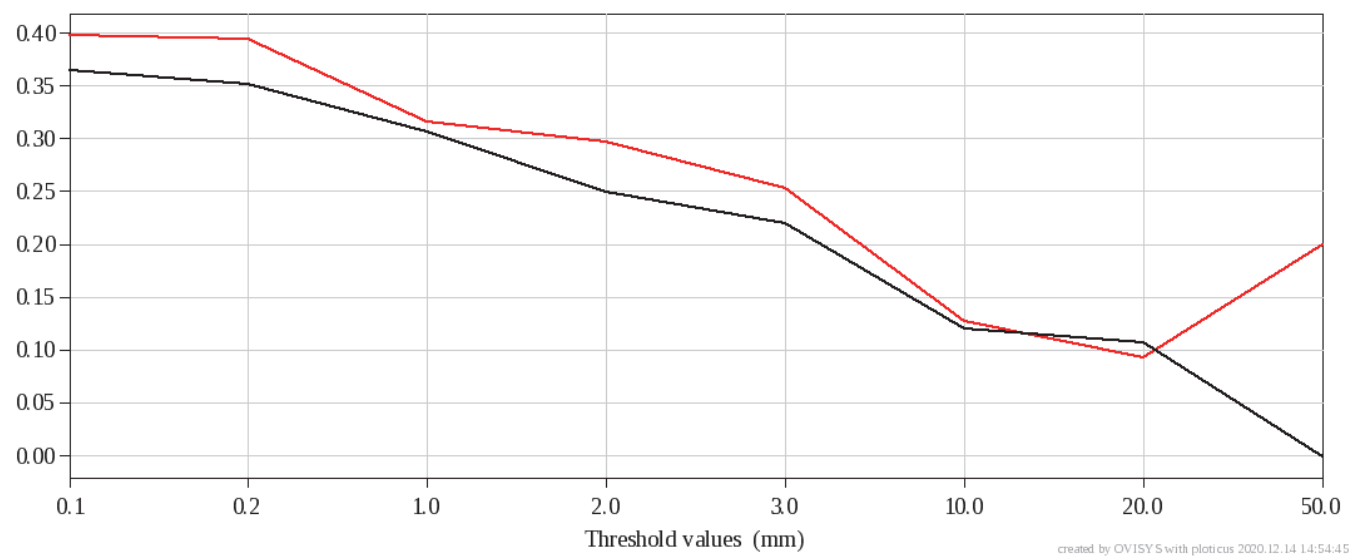

Fig. 18. ETS score of 12-hour accumulated precipitation in the 9 UTC runs from June 1 to 30, 2020. Red line: experiment with Czech Mode-S data, black line: reference run.

Regarding the upper-air variables, verification results are similarly varied. The inclusion of Mode-S MRAR data improves the forecast of some upper-air variables considerably, such as wind speed on different atmospheric levels 
(Fig. 19), but in most cases, the improvement is smaller. Other variables, such as upper-air temperature or relative humidity show similar improvement, but in some cases, the verification results for these variables are worse than those yielded by the reference run.

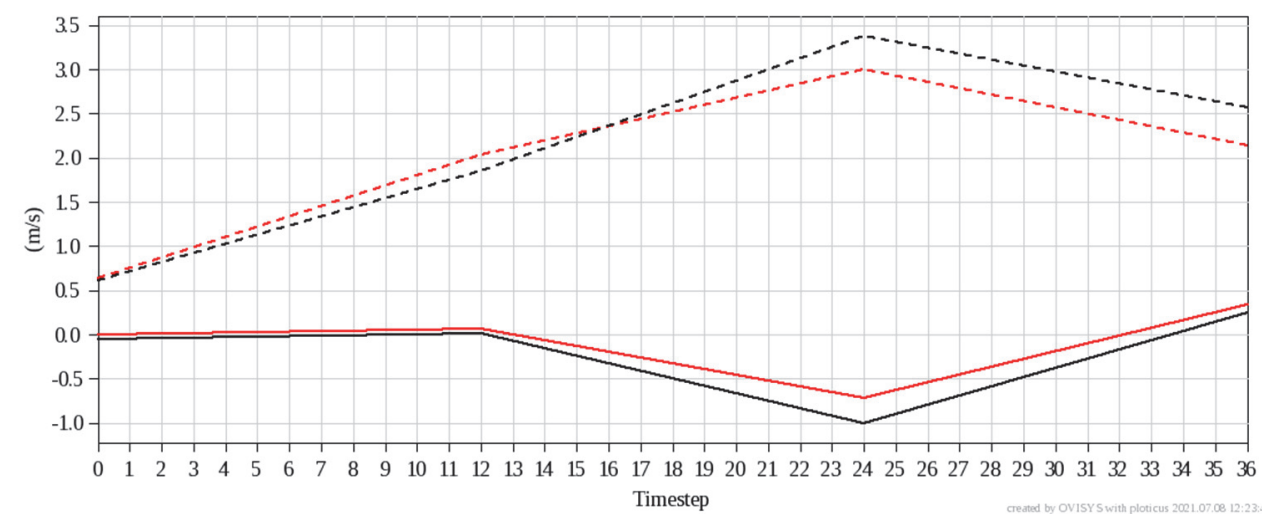

Fig. 19. Bias (solid line) and RMSE (dashed line) of $500 \mathrm{hPa}$ wind speed in the $12 \mathrm{UTC}$ runs from June 1 to 30, 2020. Black and red lines represent the reference run and the experiment using Mode-S data, respectively.

In conclusion, the assimilation of Czech Mode-S MRAR data has a small, but in most cases positive (or neutral) impact on AROME/HU forecasts. In the case of the summer experiment, the small differences can be attributed to the low number of active observations. The impact is greater at the upper atmospheric levels (for both experiments), while smaller on the surface. The assimilation of the Czech Mode-S MRAR data has been introduced operationally in AROME/HU from March 2021.

\subsubsection{Impact of the Hungarian Mode-S MRAR dataset in AROME/HU}

As a result of the positive experience with the Czech MRAR dataset, the Hungarian MRAR observations have also been investigated. Since the collection of Hungarian Mode-S data was started in November 2019, a proper preprocessing was needed on the raw dataset before their assimilation trial. Our first test period covered by the Hungarian MRAR data was between November 25, 2019 and March 31, 2020. First, a format conversion of the dataset was necessary to share the same format as other MRAR data distributed by the OPLACE system. Then a statistical quality filtering was applied, i.e., whitelisting procedure using an adopted criteria system through a passive assimilation cycle (Table 3). We only modified the minimum number of the measured data according to the flight numbers in the Hungarian flight area (Table 4). 
Table 3. The applied whitelisting criteria.

\begin{tabular}{lccc}
\hline \hline & Temperature & Wind speed & Wind direction \\
\hline \hline Mean & $1 \mathrm{~K}$ & $1 \mathrm{~m} / \mathrm{s}$ & $10^{\circ}$ \\
$\begin{array}{l}\text { Standard deviation } \\
\begin{array}{l}\text { Minimum number } \\
\text { of observations }\end{array}\end{array}$ & $2 \mathrm{~K}$ & $5 \mathrm{~m} / \mathrm{s}$ & $100^{\circ}$ \\
\hline
\end{tabular}

Table 4: Changes in the number of measurements and flights due to the whitelisting. Test period: November 25, 2019 to March 31, 2020.

\begin{tabular}{lcccc}
\hline \hline & Temperature & $\begin{array}{c}\text { Number of } \\
\text { flights }\end{array}$ & $\begin{array}{c}\text { Wind } \\
\text { (speed and direction) }\end{array}$ & $\begin{array}{c}\text { Number of } \\
\text { flights }\end{array}$ \\
\hline \hline $\begin{array}{l}\text { Total number } \\
\begin{array}{l}\text { After statistical } \\
\text { check }\end{array}\end{array}$ & 799452 & 238 & 798904 & 238 \\
After quality check & $571480(92.7 \%)$ & 114 & $740962(92.7 \%)$ & 114 \\
\hline
\end{tabular}

The test forecasts with the quality-controlled MRAR dataset were running between December 1 and 18, 2019. Significant part of the Hungarian MRAR data has been rejected in the assimilation, only a few hundreds of them remained.

Only small differences have been detected in comparison with the reference upper air wind forecasts, which are more apparent in the 12 UTC runs, when there are more flights (Fig. 20). The use of Hungarian Mode-S MRAR data has a positive impact on the $2 \mathrm{~m}$ temperature and relative humidity analyses leading to small improvements in precipitation, relative humidity, total cloud cover, and wind gust forecasts. For other forecast variables, the impact is rather neutral.
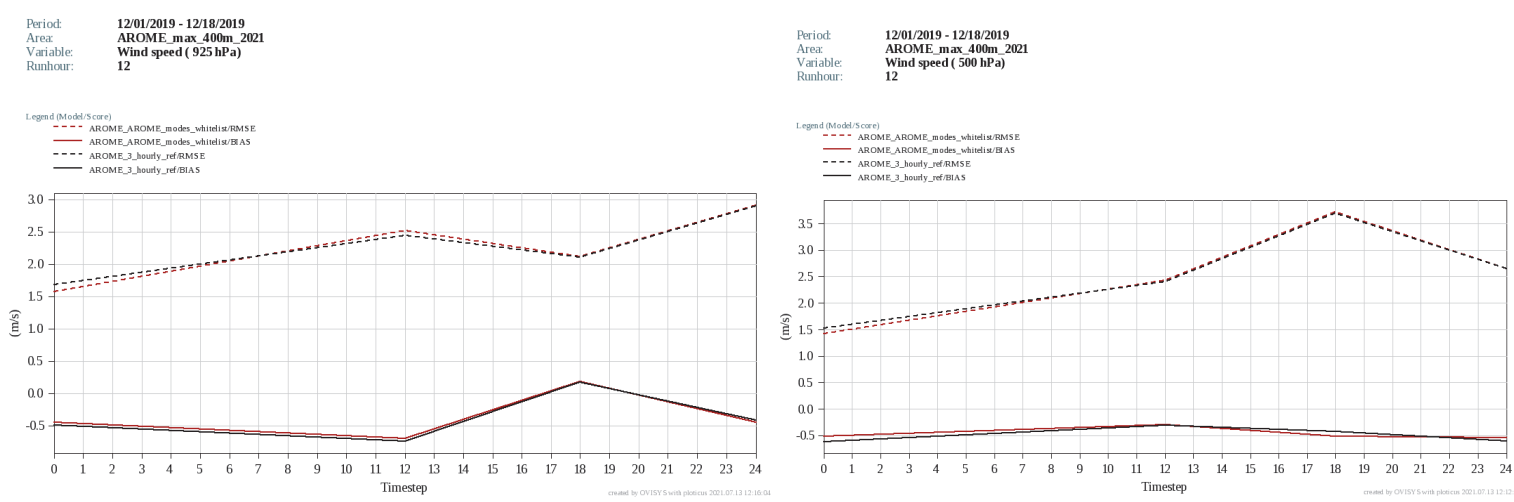

Fig. 20. RMSE (dashed line) and bias (solid line) of wind speed forecasts (left: $925 \mathrm{hPa}$, right: $500 \mathrm{hPa}$ ) at the $12 \mathrm{UTC}$ runs with assimilated Hungarian Mode-S measurements (red) and reference forecast (black) for December 1-18, 2019. 
To introduce the Hungarian Mode-S MRAR data into the operational assimilation, a further experiment is necessary on a period not (or less) affected by the pandemic.

\subsection{Impact of AMDAR-humidity in AROME/HU}

In 2015 and 2016, nine Lufthansa aircrafts were equipped with WVSS-II humidity sensors $(W M O, 2019)$, and the measured data became part of the standard AMDAR report. As upper-air humidity observations in the assimilation system of AROME/HU are currently limited to radiosondes and GNSS ZTD, AMDARhumidity data is important, especially, during the ascending or descending phases when the vertical humidity structure of the atmosphere is measured by the aircraft. The first experiments with AMDAR-humidity at OMSZ began in early 2016, and it was included in the operational assimilation system of AROME/HU in autumn 2016.

The impact of AMDAR-humidity on AROME forecasts was tested on a summer and winter period of one month each and on selected case studies. Verification scores show a generally neutral impact. Some small improvements can be observed for cloud cover in the first forecast hours and for upper-air humidity, especially for forecasts starting at 9 and 15 UTC, when no radiosonde observations are available on the AROME/HU domain (not shown).

Radiosonde and aircraft humidity data were compared when both observation types were available. Visual check of vertical profiles shows a good agreement between the two measurements (not shown). When a single specific humidity profile from AMDAR report was assimilated, the vertical profiles of the first guess and the analysis indicated that the humidity profile is closer to the observations, but without these measurements this is not the case (Fig. 21). 


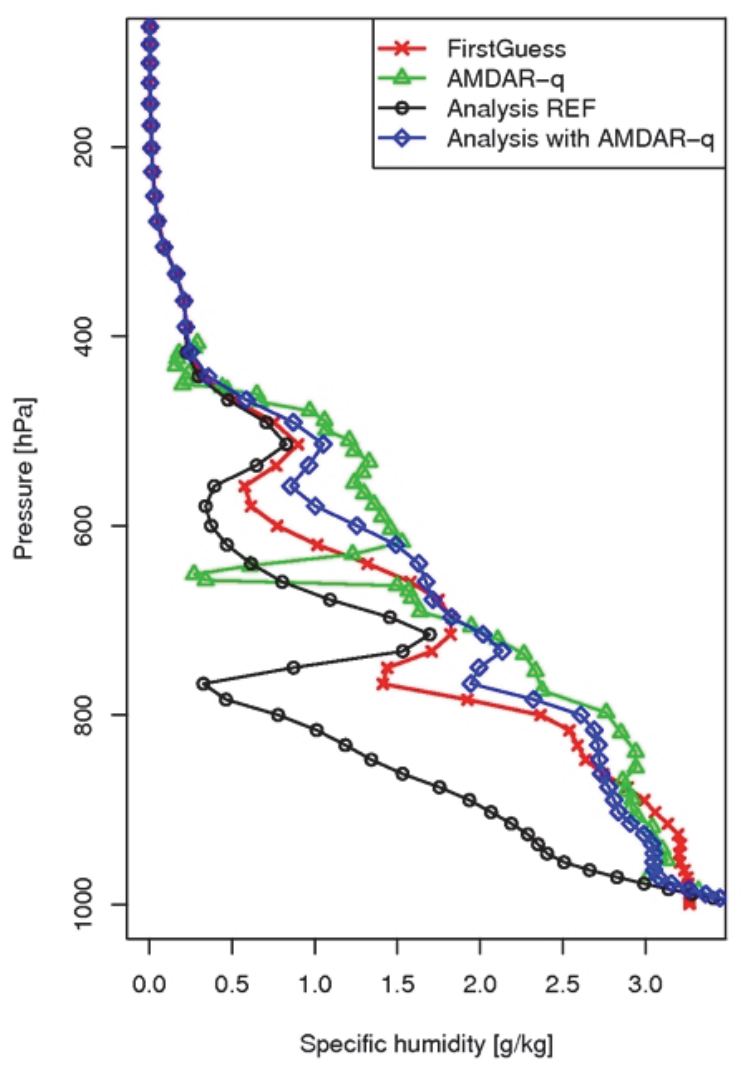

Fig. 21. Vertical profiles of specific humidity of AMDAR (green), first guess (red), analysis without AMDAR-q (black), and analysis with AMDAR-q (blue) at 18UTC, on March 25, 2016 over Budapest.

For case studies involving convection, impact of AMDAR-humidity can be more pronounced. Fig. 22 shows AROME/HU forecasts for a day with intense summer convection. It can be noted that AMDAR-humidity improves the forecast of convective precipitation in the first forecast hours: convective cells missing in the control run over the southern part of Hungary are well forecasted in the run using AMDAR-humidity.

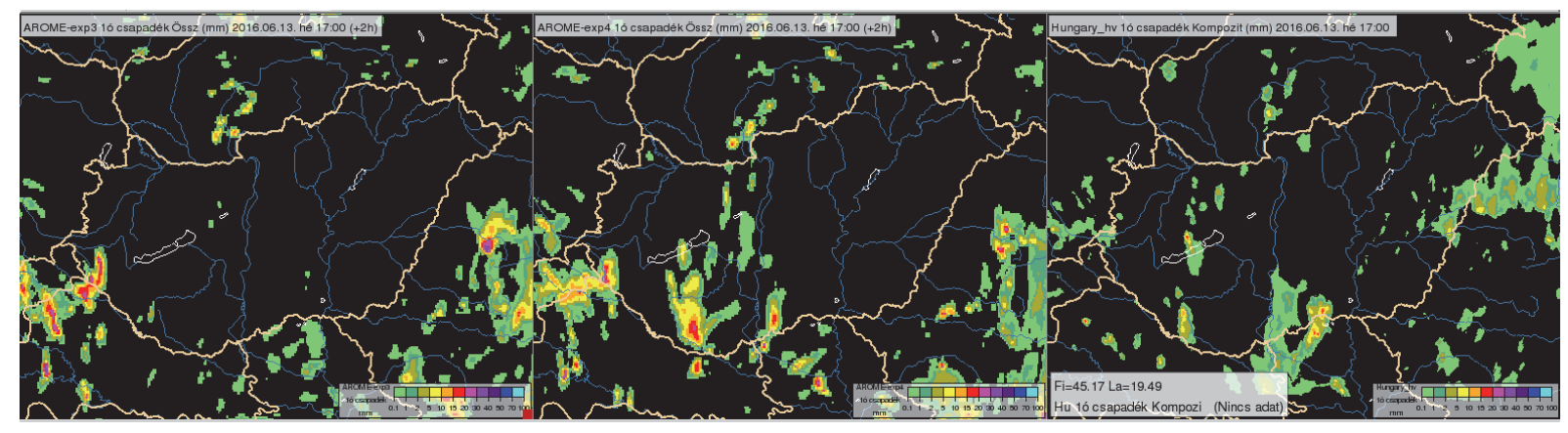

Fig. 22. Hourly precipitation sums at 17 UTC, on June 13, 2016. Right: Radar observation; left: AROME/HU run without AMDAR-humidity; middle: AROME/HU run with AMDAR-humidity (both forecasts started at 15 UTC on the same day). 
Due to the COVID-19 pandemic in 2020, the air traffic has changed dramatically, which has affected the density of AMDAR data, as well as the quality of the forecasts (Ingleby et al., 2020). As Fig. 23 shows, a few measurements arrived over the AROME/HU domain during the European springtime lockdown, and although the number of observations began to increase during the summer, it has been gradually decreasing since autumn. Only a few aircraft are equipped with humidity sensors, so in the current situation, unfortunately, AMDAR humidity observations can be assimilated very rarely in the model.

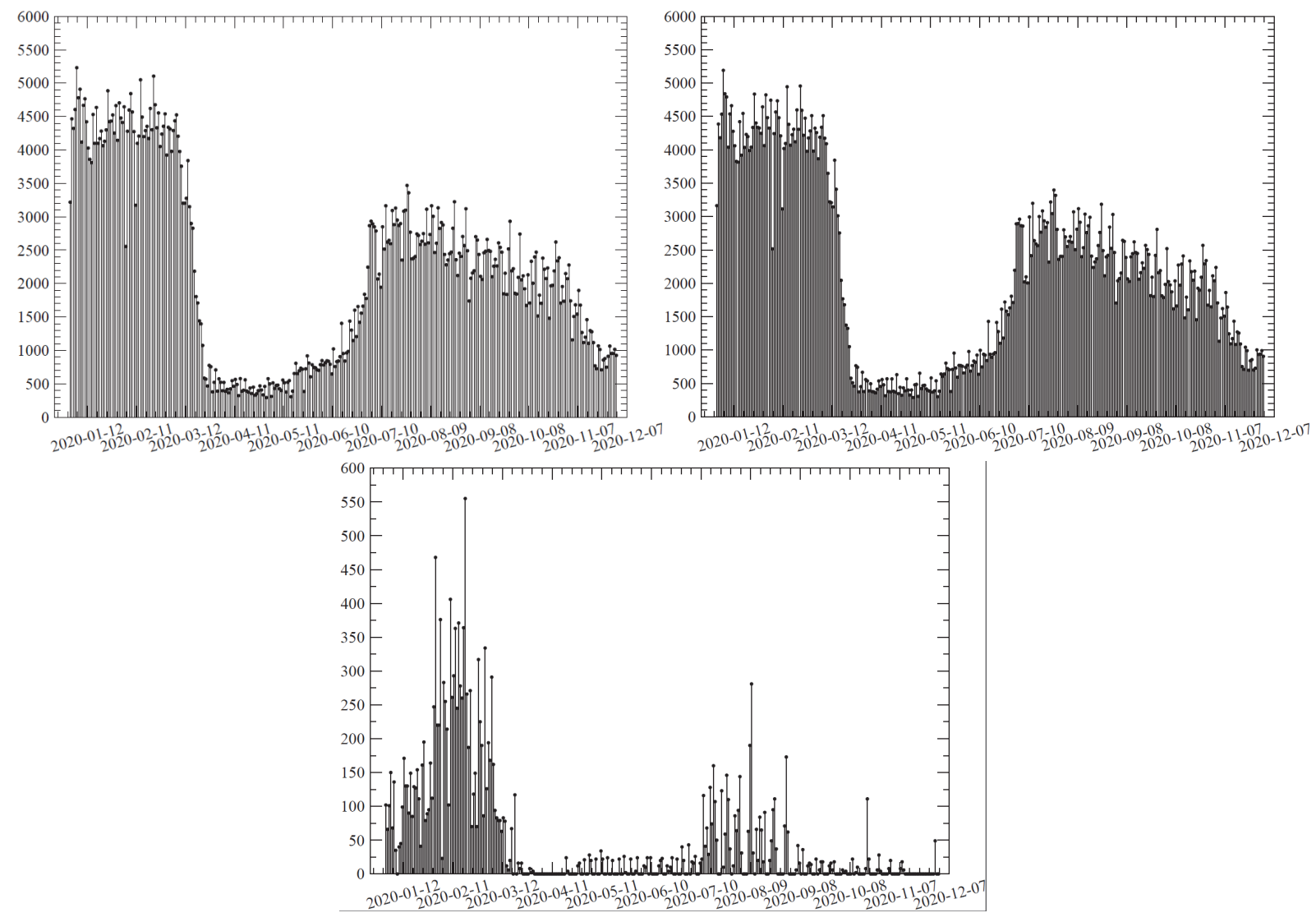

Fig. 23. Temperature (upper left), wind (upper right), and humidity (bottom) measurements over AROME/HU domain based on AMDAR reports from January to December, 2020.

\subsection{Impact of atmospheric motion vectors}

Atmospheric motion vectors (AMV) are retrieved from consecutive satellite images tracking coherent features thus estimating atmospheric wind at certain levels. AMVs have been used in data assimilation since the 1990s (Schmetz et al., 1993). The European Organization for the Exploitation of Meteorological Satellites (EUMETSAT) provides hourly AMV products (geowind from now on) 
using Meteosat Second Generation (MSG) visible, water-vapor, and infrared channel data (Borde et al., 2014). These data are routinely received and preprocessed for OPLACE at the Hungarian Meteorological Service (OMSZ).

The Satellite Application Facility on Nowcasting and Short-Range Forecasting (NWCSAF) provides a software package to calculate products supporting nowcasting locally. One of these products is the high resolution wind (HRW) (Garcia-Perada, 2018) which is generated at OMSZ. HRW (from now on hrwind) is calculated using MSG visible, water-vapor, and infrared channel data.

AMVs are successfully used in both global and regional NWP models (Forsythe et al., 2014). OMSZ has been operationally assimilating geowind in ALADIN-HU for many years (Randriamampianina, 2006). Experimental assimilation of both geowind and hrwind data were made in AROME/HU for different periods using the same settings described in Mile et al., (2015). During the spring and summer experiments, we observed a very small, mostly neutral impact of the AMV data for the surface parameters (temperature, humidity, wind, pressure - not shown). In the convective period, a small, rather positive effect can be seen for the surface wind gust (Fig. 24).

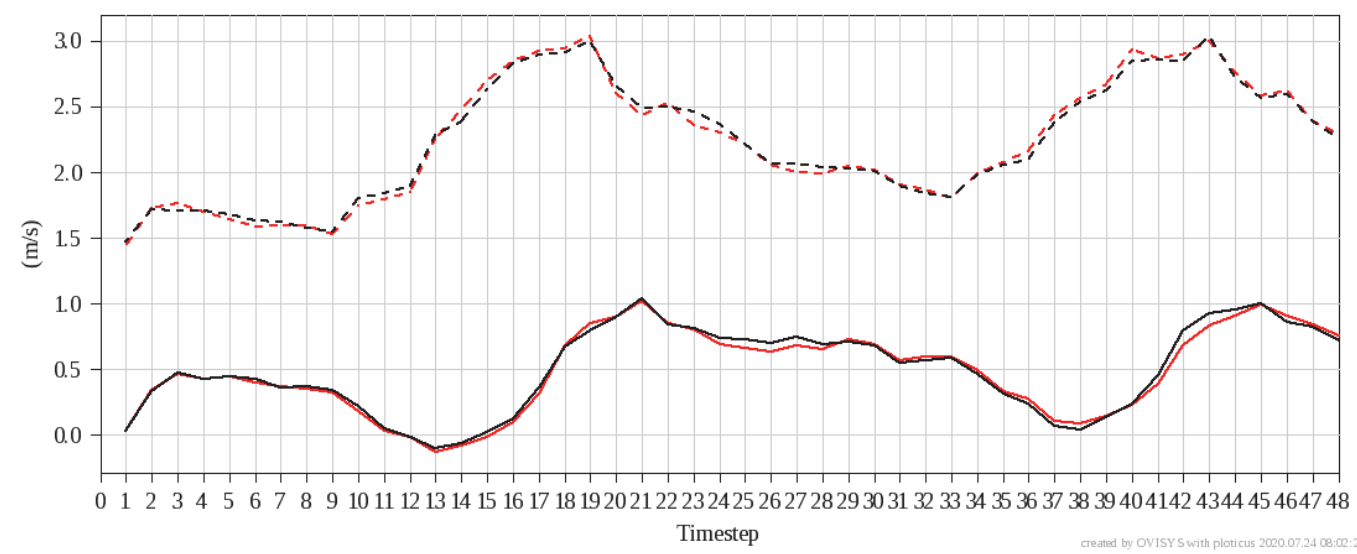

Fig. 24. Bias (solid line) and RMSE (dashed line) of wind gust forecasts in the 0 UTC runs from July 5 to August 7, 2019 as a function of lead time. Red and black lines: AROME/HU with and without AMVs, respectively.

In the precipitation, larger differences could be observed with and without AMVs. Fig. 25 shows the SEDI parameter of 24-hour precipitation amount. For days with very small and large precipitation amounts, a positive impact can be seen, while for moderate precipitation amounts, the reference model run performed better. 


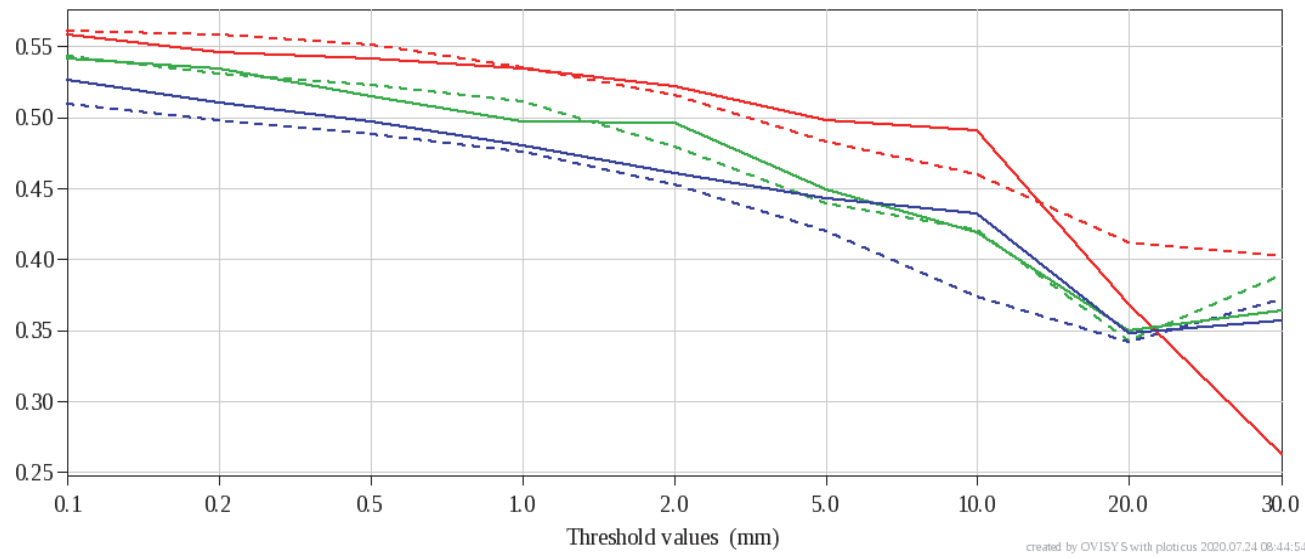

Fig. 25. SEDI of 24-hour precipitation forecasts in the 0 and 12 UTC runs from July 5 to August 7, 2019 as a function of precipitation amount at 24 (red), 36 (green), and 48 (blue) time steps. Dashed and solid lines: AROME/HU with and without AMVs, respectively.

In Fig. 26 an example is shown, where cells with small precipitation were better formed when AMVs were assimilated. In this case, both the reference and the test version struggled to forecast the right location of the precipitation.

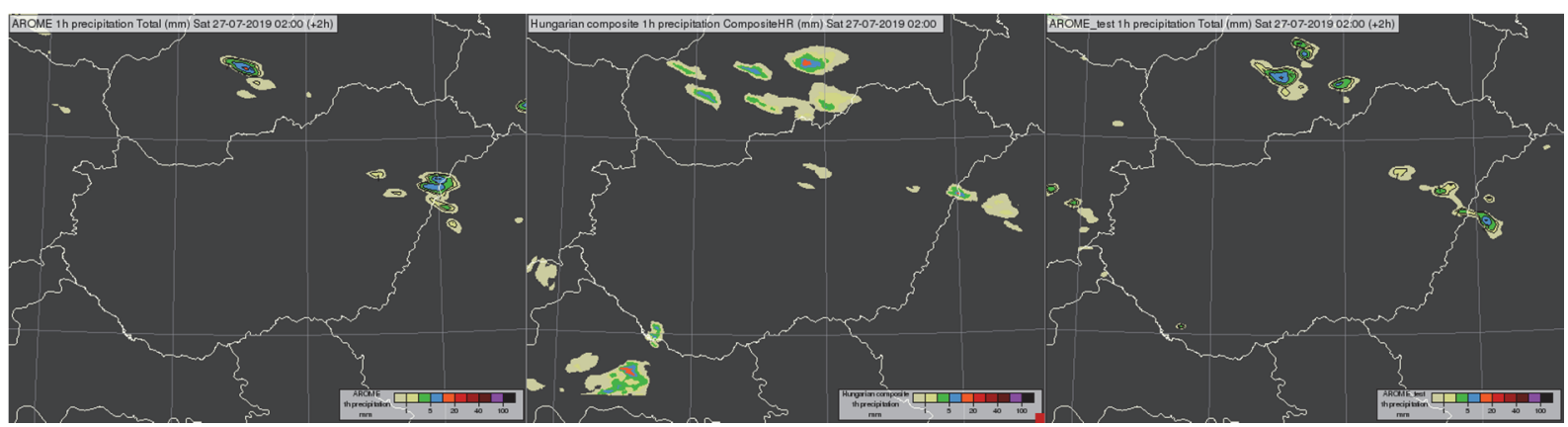

Fig. 26. 2-hour forecast of hourly precipitation without (left) and with (right) AMVs at 2 UTC, on July 27, 2019. Hourly precipitation sum based on radar data at 2 UTC, on July 27, 2019 (middle).

For the winter period, the impact of the used AMVs was mostly neutral for the surface pressure, wind speed, and wind gust. For the $2 \mathrm{~m}$ temperature and dew point, we observed a slightly negative effect (Fig. 27). Verification for the vertical levels was also done, where we could see a positive impact on wind speed (Fig. 27). However, since only a small number of radiosonde measurements are available besides 0 and 12 UTC over AROME/HU, the significance level of those results is not very high. 

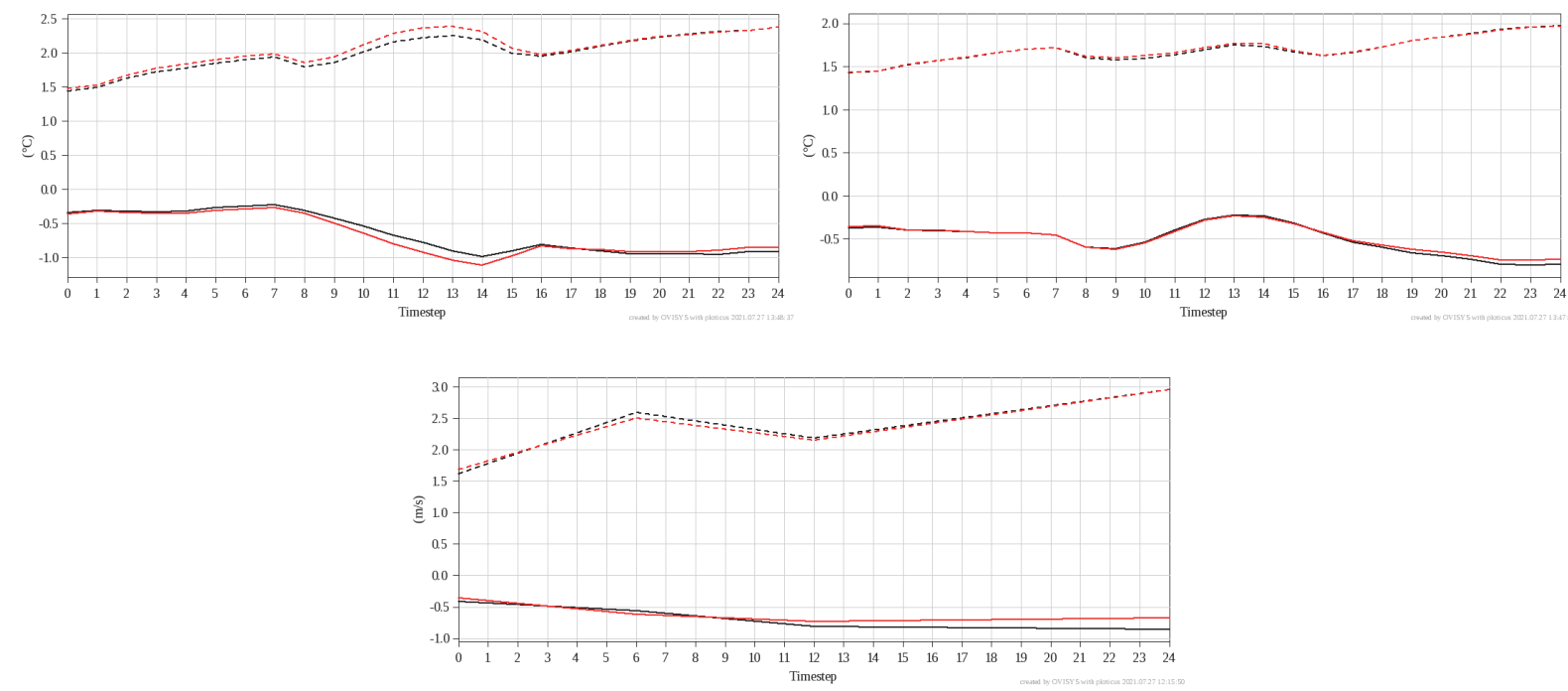

Fig. 27. Bias (solid line) and RMSE (dashed line) of $2 \mathrm{~m}$ temperature (upper left), dew point (upper right), and wind speed at $500 \mathrm{hPa}$ (bottom) forecasts in the $0 \mathrm{UTC}$ runs from December 1 to 18,2019 as a function of lead time. Black and red lines: AROME/HU without and with AMVs, respectively.

For all experiments, the used blacklisting settings (Mile et al., 2015) caused a relatively low number of active AMVs (Fig. 28). Additional experiments were configured and run to increase the number of active AMVs, and to check their distribution and characteristics. One experiment (called AMV8 hereafter) was for the activation of mid-tropospheric AMVs, which data were blacklisted a long time ago assuming their height assignment is less accurate, and another experiment (called AMVA hereafter) was carried out to allow even more previously blacklisted data into the assimilation system. Table 5 describes the different settings and blacklisting details.

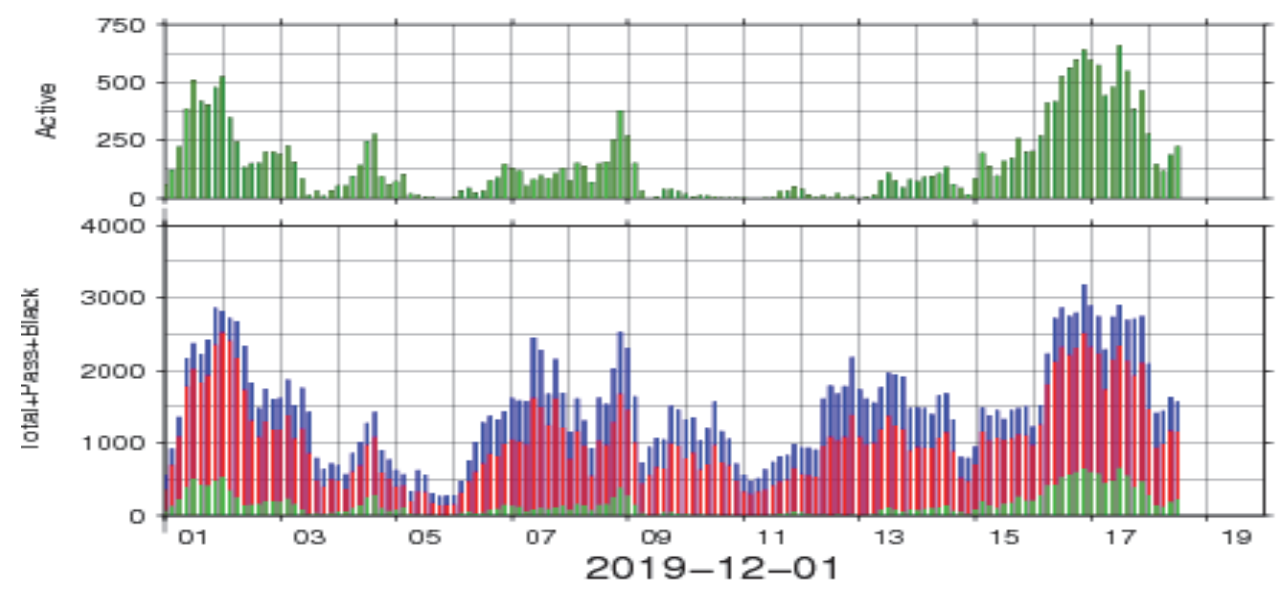

Fig. 28. Number of AMV observations over the AROME/HU domain from December 1 to 18,2019 . The numbers of blacklisted, rejected, and active observations are shown with blue, red, and green color. 
Table 5: Blacklisting settings.

\begin{tabular}{lccc}
\hline \hline Setting & Reference & AMV8 & AMVA \\
\hline \hline Quality index $<85 \%$ & inactive & inactive & inactive \\
Data where $\mathrm{p}>700 \mathrm{hPa}$ over land & inactive & inactive & active \\
Data where $\mathrm{p}<700 \mathrm{hPa}$ for $\mathrm{VIS}$ & inactive & inactive & active \\
Data between 300 and $850 \mathrm{hPa}$ & inactive & active & active \\
Data where $\mathrm{p}>400 \mathrm{hPa}$ for $\mathrm{WV}$ & inactive & inactive & active \\
\hline
\end{tabular}

Fig. 29 shows that both AMVA and AMV8 runs activated more AMVs than the reference. AMVA uses more observation at lower levels, which may result in discrepancies due to orography. Observation minus background (O-B) statistics show no suspicious feature between 800 and $350 \mathrm{hPa}$ (Fig. 30), so proceeding with AMV8 settings seems to be a better choice in the future.
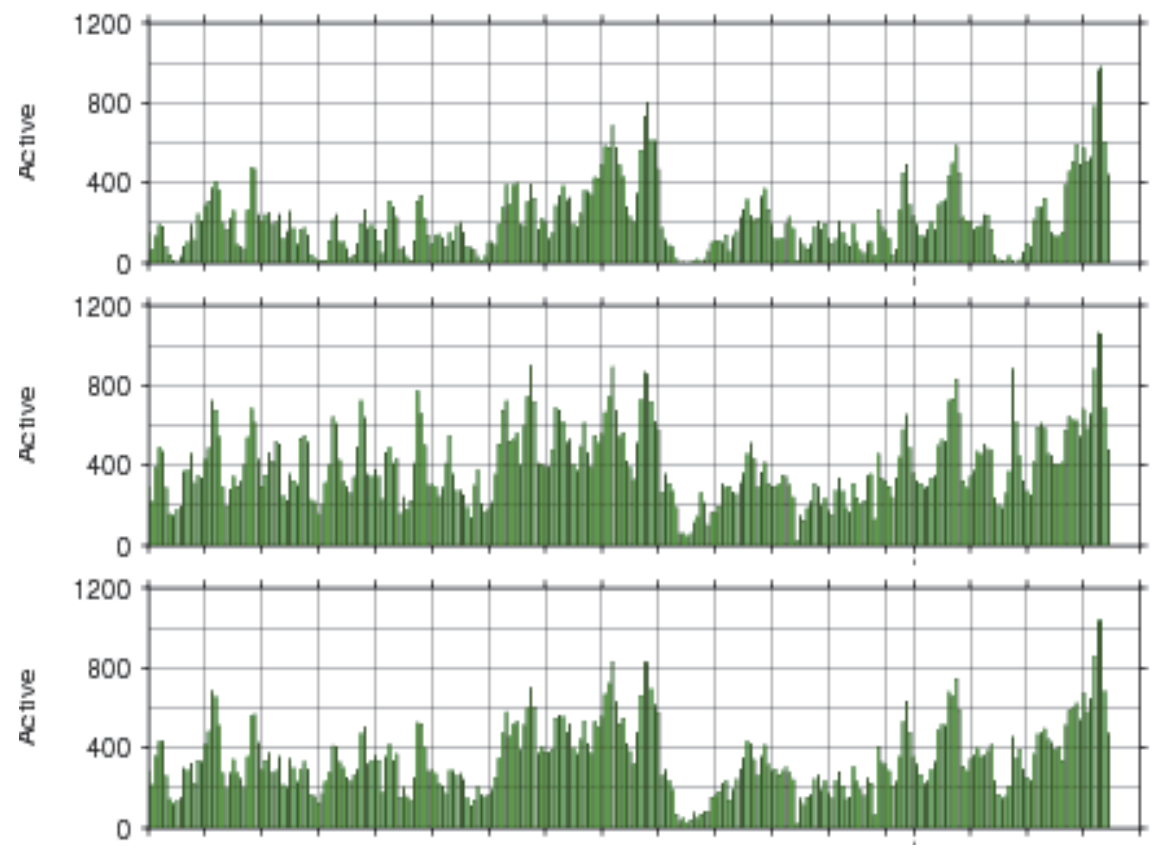

Fig. 29. Number of active AMV observations over the AROME/HU domain from July 5 to August 7, 2019 for the initial experiment (top), for experiment AMVA (middle), and for experiment AMV8 (bottom). 

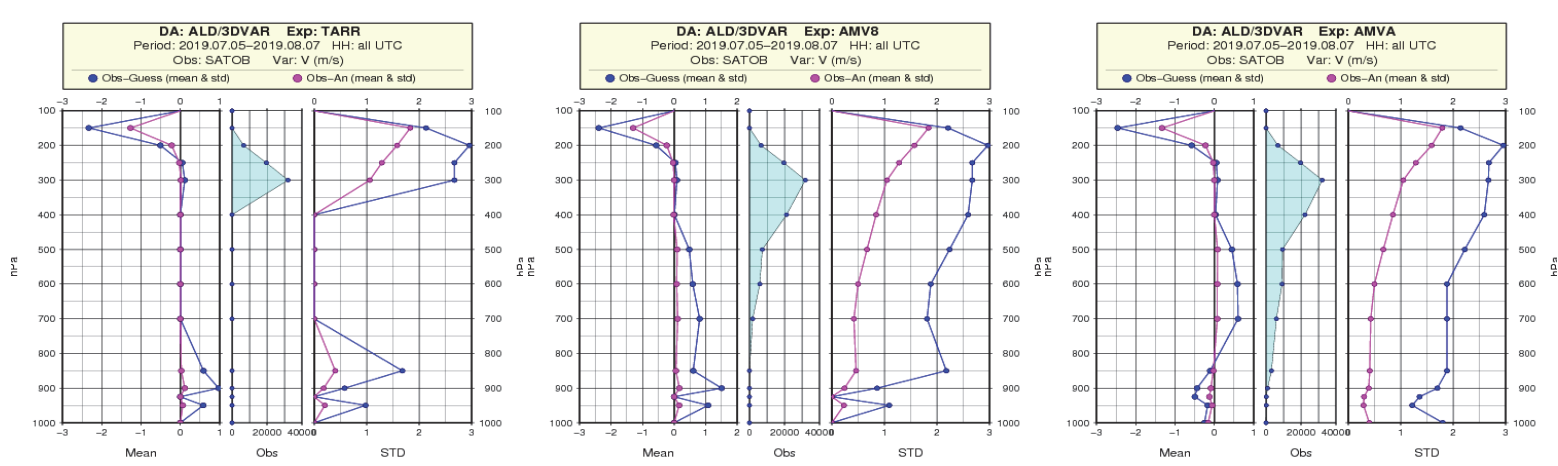

Fig. 30. The vertical distribution of the active observations for the initial experiment (left), for experiment AMV8 (middle), and for experiment AMVA (right) over the AROME/HU domain from July 5 to August 7, 2019.

\section{Summary and conclusions}

The latest developments of the AROME/HU data assimilation system were shown in this paper. First of all, the current operational DA system was described with a focus on the locally assimilated observations and special interest in the preparation mechanism of the analysis and forecast.

Then surface data assimilation developments were described. It was shown, that both the OI-main and the SEKF provided a positive impact on the screenlevel parameters compared to the dynamical adaptation of AROME/HU, especially for nighttime periods. Very promising results were demonstrated by applying a 1-hour RUC configuration compared to the 3-hour ones. The reliability of the analyses and short-range forecasts were improved by employing more observations in the DA system. However, higher accuracy was provided by reduction of surface assimilation cycle frequency, the best results were found using a 3-hourly surface assimilation interval. Thereafter, upper-air DA impact studies were carried out using different kinds of observations to improve the analyses and forecasts. The impact of Czech and Hungarian Mode-S MRAR data assimilations was slightly positive or neutral regarding the analyses and the forecasts of surface parameters. The effect of AMDAR-humidity in AROME/HU forecasts was also tested, and generally, neutral impact was obtained. However, it can be noted that AMDAR-humidity improves the convective precipitation forecast in the first hours and helps to extend slightly the humidity related observations in the assimilation system. In addition to the assimilation of conventional data, non-conventional AMV data has been tested in AROME/HU DA system. Due to the outdated AMV blacklisting settings, an experiment was performed by the activation of mid-tropospheric AMVs to allow more data into the assimilation system. The upper-level innovation of this new experiment has shown promising results for further studies.

This paper indicated, that applying new methods, as SEKF, more frequent RUC, or increasing the number of new assimilated observations, like additional 
aircraft or AMV observations, are future perspectives and powerful tools to improve the mesoscale analyses and forecasts. The AMDAR-humidity and the Czech Mode-S MRAR data are already part of the AROME 3D-Var operational system. The implementation of new, high resolution observations in the DA system, such as radar observations or satellite data, are becoming highly important, as the horizontal and vertical resolution of the meteorological model is continuously growing. In addition, we have to pay attention to modeling of the background error covariance matrix for the higher resolution model version, which is based on AROME ensemble DA method.

Acknowledgements: The authors would like to thank Gergely Bölöni, Roger Randriamampianina, and Máté Mester for their former studies on data assimilation developments at the Hungarian Meteorological Service. Special thanks go to the Péter Kardos and Imre Bányász at HungaroControl for providing Hungarian Mode-S test data. We are grateful to the editors, that our article can be published in this anniversary special issue of Idojárás. The authors would like to express their gratitude to the two anonymous reviewers for their detailed and valuable reviews.

\section{References}

Albergel, C., Munier, S., Leroux, D. J., Dewaele, H., Fairbairn, D., Barbu, A. L., Gelati, E., Dorigo, W., Faroux, S., Meurey, C., Le Moigne, P., Decharme, B., Mahfouf, J.-F., and Calvet, J.-C., 2017: Sequential assimilation of satellite-derived vegetation and soil moisture products using SURFEX_v8.0: LDAS-Monde assessment over the Euro-Mediterranean area, Geosci. Model Dev. 10, 3889-3912. https://doi.org/10.5194/gmd-10-3889-2017

Barbu, A. L., Calvet, J.-C., Mahfouf, J.-F., and Lafont, S., 2014: Integrated ASCAT surface soil moisture and GEOV1 leaf area index into the SURFEX modelling platform: a land data assimilation application over France, Hydrol. Earth Syst. Sci. 18, 173-192.

https://doi.org/10.5194/hess-18-173-2014

Benjamin, S.G., Dévényi, D., Weyandt, S.S., Brundage, K.J., Brown, J.M., Grell, G.A., Kim, D., Schwartz, B.E., Smirnova, T.G., Smith, T.L., and Manikin, G.S., 2004: An hourly assimilationforecast cycle: The RUC. Mon. Weather Rev., 132, 495-518.

https://doi.org/10.1175/1520-0493(2004)132<0495:AHACTR>2.0.CO;2

Berre, L., 2000: Estimation of synoptic and mesoscale forecast error covariances in a limited area model. Mon. Weather Rev. 128, 644-667. https://doi.org/10.1175/1520-0493(2000)128<0644:EOSAMF>2.0.CO;2

Borde, R.; Carranza, M.; Hautecoeur, O.; and Barbieux, K., 2019: Winds of Change for Future Operational AMV at EUMETSAT. Remote Sens. 11, 2111. https://doi.org/10.3390/rs11182111

Borde, R.; Doutriaux-Boucher, M.; Dew, G.; and Carranza, M., 2014: A Direct Link between Feature Tracking and Height Assignment of Operational EUMETSAT Atmospheric Motion Vectors. $J$. Atmos. Oceanic Technol. 31, 33-46. https://doi.org/10.1175/JTECH-D-13-00126.1

Bölöni, G., 2006: Development of a variational data assimilation system for a limited-area model at the Hungarian Meteorological Service. Idöjárás 110, 309-327.

Bölöni, G., Berre, L., and Adamcsek, E., 2014: Comparison of static mesoscale background error covariances estimated by three different ensemble data assimilation techniques. Q. J. Roy. Meteorol. Soc. 141, 413-425. https://doi.org/10.1002/qj.2361

Cardinali, C., Pezzuli, S., and Andersson, E., 2004: Influence matrix diagnostic of data assimilation system. Q. J. Roy. Meteorol. Soc. 130, 2767-2786. https://doi.org/10.1256/qj.03.205

Courtier, P., Thépaut, J.-N., and Hollingsworth, A., 1994: A strategy for operational implementation of 4D-Var, using an incremental approach. Q. J. Roy. Meteorol. Soc. 120, 1367-1387. https://doi.org/10.1002/qj.49712051912 
Fischer, A., Homonnai, V., Mile, M., Sepsi, P., Szintai, B., and Szücs, M., 2017: Modelling activities at the Hungarian Meteorological Service. ALADIN/HIRLAM Newsletter 8, 64-68.

Fischer, A., Homonnai, V., Mester, M., Mile, M., Suga, R., Szintai, B., and Szücs, M., 2018: Modelling activities at the Hungarian Meteorological Service. ALADIN/HIRLAM Newsletter 10, 53-55.

Fischer, C., Montmerle, T., Berre, L., Auger, L., and Ştefanescu, S.E., 2005: An overview of the variational assimilation in the ALADIN/France numerical weather-prediction system. Q. J. Roy. Meteorol. Soc. 131, 3477-3492. https://doi.org/10.1256/qj.05.115

Fischer, C., 2007: The variational computations inside ARPEGE/ALADIN: cycle CY32. http://www.umr-cnrm.fr/gmapdoc/spip.php?article11\&var_lang=en, $18 p$

Forsythe M, C Peubey, C Lupu, and J Cotton, 2014: Assimilation of wind information from radiances: AMVs and 4D-Var tracing, ECMWF Annual Seminar, September 2014, available in-line at: https://www.ecmwf.int/sites/default/files/elibrary/2015/9444-assimilation-wind-informationradiances-amvs-and-4d-var-tracing.pdf

Garcia-Pereda, J., 2018: Algorithm Theoretical Basis Document for "High Resolution Winds" (NWC SAF/HRW v2018) https://doi.org/10.13140/RG.2.2.14679.91045

Giard, D. and Bazile, E., 2000: Implementation of a New Assimilation Scheme for Soil and Surface Variables in a Global NWP Model. Mon. Weather Rev. 128, 997-1015. https://doi.org/10.1175/1520-0493(2000)128<0997:IOANAS>2.0.CO;2

Hágel, E., 2009: Development and operational application of a short-range ensemble prediction system based on the ALADIN limited area model. Ph. D. dissertation, Eötvös Loránd University, Faculty of Science, $127 \mathrm{p}$.

Hess, R., 2001: Assimilation of screen-level observations by variational soil moisture analysis. Meteorol. Atmos. Phys. 77, 145-154. https://doi.org/10.1007/s007030170023

Horányi, A., Ihász, I., and Radnóti, G., 1996: ARPEGE/ALADIN: a numerical weather prediction model for Central-Europe with the participation of the Hungarian Meteorological Service. Idöjárás 100, 277-301.

Ingleby, B., Candy, B., Eyre, J., Haiden, T., Hill, Ch., Isaksen, L., Kleist, D., Smith, F., Steinle, P., Taylor, S., Tennant, W., and Tingwell, Ch., 2020: The Impact of COVID-19 on weather forecasts: a balanced view. Geophys. Res. Lett. 48, e2020GL090699.

https://doi.org/10.1029/2020GL090699

Jávorné Radnóczi, K., Várkonyi, A., and Szépszó, G., 2020: On the way towards the AROME nowcasting system in Hungary. ALADIN/HIRLAM Newslett., 14, 65-69.

Lynch, P., D. Giard, and V. Ivanovici, 1997: Improving an efficiency of Digital Filtering Scheme for Diabatic Initialization. Mon. Weather Rev. 125, 1976-1982. https://doi.org/10.1175/1520-0493(1997)125<1976:ITEOAD >2.0.CO;2

Mahfouf J.-F., Viterbo P., Douville H., Beljaars A., and Saarinen S., 2000: A Revised land-surface analysis scheme in the Integrated Forecasting System. ECMWF Newslett. 88.

Mahfouf, J.-F., K. Bergaoui, C. Draper, F. Bouyssel, F. Taillefer, and L. Taseva, 2009: A comparison of two off-line soil analysis schemes for assimilation of screen level observations, J. Geophys. Res., 114, D08105. http://dx.doi.org/10.1029/2008JD011077.

Masson, V., Le Moigne, P., Martin, E., Faroux, S., Alias, A., Alkama, R., Belamari, S., Barbu, A., Boone, A., Bouyssel, F., Brousseau, P., Brun, E., Calvet, J.-C., Carrer, D., Decharme, B., Delire, C., Donier, S., Essaouini, K., Gibelin, A.-L., Giordani, H., Habets, F., Jidane, M., Kerdraon, G., Kourzeneva, E., Lafaysse, M., Lafont, S., Lebeaupin Brossier, C., Lemonsu, A., Mahfouf, J.-F., Marguinaud, P., Mokhtari, M., Morin, S., Pigeon, G., Salgado, R., Seity, Y., Taillefer, F., Tanguy, G., Tulet, P., Vincendon, B., Vionnet, V., and Voldoire, A., 2013: The SURFEXv7.2 land and ocean surface platform for coupled or offline simulation of earth surface variables and fluxes. Geosci. Mod. Dev. 6, 929-960. https://doi.org/10.5194/gmd-6-929-2013.

Mile, M., Bölöni, G., Randriamampianina, R., Steib, R., and Kucukkaraca, E., 2015: Overview of mesoscale data assimilation developments at the Hungarian Meteorological Service. Idójárás 119, 215-239.

Mile, M., Benáček, P., and Rózsa, Sz., 2019: The use of GNSS zenith total delays in operational AROME/Hungary 3D-Var over a central European domain. Atmos. Meas. Tech. 12, 1569-1579. https://doi.org/10.5194/amt-12-1569-2019 
Noilhan, J. and S. Planton, 1989: A simple parameterization of land surface processes for meteorological models. Mon. Weather Rev. 117, 536-549.

https://doi.org/10.1175/1520-0493(1989)117<0536:ASPOLS $>2.0 . C O ; 2$

Noilhan, J. and Mahfouf, J.-F., 1996: The ISBA land surface parameterisation scheme. Glob. Planet. Change 13, 145-159. https://doi.org/10.1016/0921-8181(95)00043-7.

Parrish, D.F. and Derber, J.C., 1992: The National Meteorological Center's spectral statistical interpolation analysis system. Mon. Weather Rev. 120, 1747-1763. https://doi.org/10.1175/1520-0493(1992)120<1747:TNMCSS >2.0.CO;2

Randriamampianina, R., 2006: Impact of high resolution observations in the ALADIN/HU model. Időjárás 110, 329-349.

de Rosnay, P., Drusch, M., Vasiljevic, D., Balsamo, G., Albergel, C., and Isaksen, L., 2013: A simplified Extended Kalman Filter for the global operational soil moisture analysis at ECMWF. Q. J. Roy. Meteorol. Soc. 139, 1199-1213. https://doi.org/10.1002/qj.2023

Rüdiger, C., C. Albergel, J.-F. Mahfouf, J.-C. Calvet, and J. P. Walker, 2010: Evaluation of the observation operator Jacobian for leaf area index data assimilation with an extended Kalman filter, J. Geophys. Res. 115, D09111. https://doi.org/10.1029/2009JD012912

Schmetz J, Holmlund K, Hoffman J, and Strauss B., 1993: Operational cloud-motion winds from Meteosat infrared images. J. Appl. Meteorol. 32, 1206-1225. https://doi.org/10.1175/1520-0450(1993)032<1206:OCMWFM >2.0.CO;2

Seity, Y., Brousseau, P., Malardel, S., Hello, G., Bénard, P., Bouttier, F., Lac, C., and Masson, V., 2011: The AROME-France Convective-Scale Operational Model. Mon. Weather Rev. 139, 976-991. https://doi.org/10.1175/2010MWR3425.1

Szintai, B., Szücs, M.., Randriamampianina, R., and Kullmann, L.., 2015: Application of AROME nonhydrostatic model at the Hungarian Meteorological Service: physical parametrizations and ensemble forecasting. Idöjárás 119, 241-265.

Strajnar B., 2012: Validation of Mode-S Meteorological Routine Air Report aircraft observations. $J$. Geophys. Res. 117, D231110. https://doi.org/10.1029/2012JD018315

Taillefer, F., 2002: CANARI (Code for the Analysis Necessary for Arpege for its Rejects and its Initialization): Technical documentation. Internal CNRM/GMAP Report, $55 \mathrm{pp}$.

Tóth, H., 2004: Detailed case study of a dramatic winter temperature overestimation in the ALADIN/HU model. RC LACE Internal Report. 10pp, http://rclace.eu/?page=11)

Trojáková, A., Mile, M., and Tudor, M., 2019: Observation Preprocessing System for RC LACE (OPLACE). Adv. Sci. Res. 16, 223-228., https://doi.org/10.5194/asr-16-223-2019

Wernli, H., Paulat, M., Hagen, M., and Frei, C. 2008:. SAL-A Novel Quality Measure for the Verification of Quantitative Precipitation Forecasts. Month. Weather Rev. 136, 4470-4487. https://doi.org/10.1175/2008mwr2415.1

World Meteorological Organization, 2019: Tests, Comparisons and Operational Performance of the Water Vapor Sensing Systems (WVSS-II): CIMO Expert Team on Aircraft-based Observations. 